\title{
The Integrative Power of Civic Networks ${ }^{1}$
}

\author{
Delia Baldassarri \\ Princeton University \\ Mario Diani \\ University of Trento
}

This article analyzes integrative dynamics within civil society by looking at civic networks - the web of collaborative ties between participatory associations acting on behalf of public and collective interests. Drawing upon evidence from Glasgow and Bristol, the authors identify a polycentric model of civic coordination based on horizontal solidarity, in which associations form dense clusters of strong identity ties ("social bonds") bridged by fewer instrumental ties ("transactions"). Basic relational mechanisms, consistent across localities, provide the basis for both micro- and macrointegration: they generate networks tight enough to embed civic associations in a distinctive environment, but open enough to connect them to a broader range of civic organizations. While contributing primarily to the understanding of political networks, the authors' findings also have implications for current debates on associational social capital and the impact of political contexts on the structure of collective action.

\section{INTRODUCTION}

In democratic regimes, associations not only represent specific interests, but also reach out, integrate, and mediate among diverse, sometimes al-

${ }^{1}$ This article originates from an investigation of networks of civic organizations in
Britain that Mario Diani conducted with Isobel Lindsay (University of Strathclyde in
Glasgow) and Derrick Purdue (University of West of England, Bristol) from 2000 to
2003. The project was part of the Democracy and Participation Program, funded by
the Economic and Social Research Council (contract L215 25 2006) and directed by
Paul Whiteley. Earlier versions of this argument were presented at the Sunbelt Social
Networks Conference in Portorose, Slovenia, April 2004; the annual meeting of the
American Sociological Association, San Francisco, August 2004; the European Science
Foundation seminar "The Collection and Analysis of Network Data," Ljubljana, July
2005; the Equalsoc Summer School, Trento, September 2006; and at seminars at the
University of California-Los Angeles, Harvard University, the University of Chicago,

(C) 2007 by The University of Chicago. All rights reserved.

0002-9602/2007/11303-0004\$10.00 


\section{American Journal of Sociology}

ternative interests or ideological standpoints. The extent to which they are capable of spanning across social cleavages and different social spheres is crucial in order to assess the potential of civil society to operate as a public arena for discussion, mediation, and deliberation (Kornhauser 1959; Dahl 1961; Linz 1967; Allen 1984; Warren 2001; Edwards, Foley, and Diani 2001; Fung 2003).

Accordingly, the relationship between associational life and social integration is affected by the way in which associations relate to each other and by the structure of interorganizational relations they generate. But if this is the case, then exploring the contribution of individuals and associations to democratic life by focusing on individual participation (Paxton 1999; Putnam 2000) or on the traits of specific organizations (Minkoff 1997; Powell and Clemens 1998; Skocpol 2003; Warren 2001) may not be sufficient. One also needs to look at the properties of the networks that connect organizations to each other and thus facilitate or constrain their cross-cutting and bridging functions, as well as their overall contribution to social integration.

In this article we take a few steps in the latter direction by looking at the structure of civic networks in two British cities, Glasgow and Bristol. We define "civic networks" as the web of collaborative ties and overlapping memberships between participatory organizations, formally independent of the state, acting on behalf of collective and public interests. While many have evoked the networked structure of civil society (Cohen and Arato 1992; Diamond 1994; Edwards et al. 2001), few have so far subjected it to systematic analysis, either analytically or empirically. Here, we try to do both: we first discuss some key dimensions along which to analyze civic networks and then look at empirical evidence to prove the efficacy of this analytical framework as well as to set the parameters for further research.

Given the initial stage of this research agenda, the process of theorization, the development of analytical tools, and the empirical analysis are closely intertwined. This means that we do not present a classical hypothesis-testing analysis, but we simultaneously explore and describe the main features of civic networks, while testing some working hypotheses along the way. Moreover, we do not regard our cases as particularly relevant or worthy of attention in their own right, nor do we intend to generalize our findings. Rather, we use them to test analytical principles

and Stanford Graduate School of Business, fall 2006. We are grateful for valuable comments and suggestions from Peter Bearman, Ron Breiger, Yannick Lemel, John Padgett, Charles Tilly, Duncan Watts, Harrison White, and the AJS reviewers. Direct correspondence to Delia Baldassarri, Department of Sociology, Princeton University, 147 Wallace Hall, Princeton, New Jersey 08544. E-mail: dbalda@princeton.edu 


\section{Civic Networks}

which might—and in fact do-prove useful to our understanding of civil society processes at large.

In the first part of the article we lay out our main questions. We first ask What is the shape of civic networks in democratic society? The connections between different sectors of civil society may take a hierarchical, centralized form or take a more horizontal, polycentric form. In order to capture those differences, we focus first on the formal properties of civic networks. We differentiate at the macrolevel, between hierarchical and polycentric structures, and at the microlevel, between asymmetric or balanced organizational interdependence. The forms of civic networks provide insights into the level of potential mobilization, network robustness, and the nature of organizational interdependence.

Second, we look at the content of network ties. What types of ties may contribute to the strengthening and integration of civil society, and how? Most structural analyses of civil society, policy networks, or social movement sectors have either focused on interorganizational alliances (Laumann and Knoke 1987; Rochon and Meyer 1997; Knoke 2001; Ansell 2003) or on the ties created by multiple memberships (Carroll and Ratner 1996; Cornwell and Harrison 2004). But how do they combine? Does the distribution of those ties follow any discernible pattern? Or do they simply distribute randomly across civic networks? What do those patterns tell us about the nature of civil society? We address these questions by differentiating between two types of relationships that we call transactions and social bonds (Lémieux 1998). The former consist of alliance ties, involving exclusively the exchange of information and resources necessary to the pursuit of shared collective goals. The latter add to the former deeper, underlying links, as the pooling of resources is matched by shared core members. We suggest that organizations are involved in multiplex relational patterns in which identity relations-social bonds-embed associations into dense clusters of interaction, while instrumental relationstransactions-operate across clusters, integrating them into the broader civic network.

After introducing our core questions, we outline our research design and data collection strategy as well as the socioeconomic and political profile of the two cities, focusing on the different class and ethnic composition of the two cities, the varying levels of affluence and education, and the relative influence of the Labour Party vis-à-vis other political traditions.

We then present our empirical findings. First, we describe the formal properties of civic networks and adjudicate between the alternative hypotheses of a hierarchical versus a polycentric structure. Formal properties are investigated both at the macrolevel, by referring to graph measures, and at the level of triadic interactions. In both Glasgow and Bristol, graph 
American Journal of Sociology

measures and typical patterns of microinteraction consistently suggest civic networks to be much closer to polycentric, decentralized structures based on balanced forms of interdependence than to hierarchical, centralized structures based on asymmetric forms of interdependence. Civic organizations tend to gather in clusters of dense exchange and interaction while they maintain levels of connectivity typical of integrated networks.

Then we show how such formal properties arise from patterns of local interaction. The clustering and connectivity properties of a polycentric structure are the by-product of the peculiar intersection of two types of links: transactions and social bonds. While social bonds characterize areas of intense interactions, transactions bridge those areas.

Finally, we look at the associational logics that induce organizations to engage in such relational patterns. Civic organizations develop in-depth relations with organizations with the same interests and develop instrumental, ad hoc alliances with organizations that are only marginally committed to their main goals. Consequently, they generate a web of interactions tight enough to embed them in a distinctive environment, but open enough to connect them to a broader and more heterogeneous group of civic organizations.

In the conclusions, we summarize the polycentric model of civic coordination that emerges from the research. We argue that civic networks contribute to social integration when associations manage to achieve a balance between instrumental relationships and ties that imply deeper affective bonding. We also illustrate the implications of this finding for current debates on associational life and social capital, as well as on the influence of the political context over network structures.

\section{KEY DIMENSIONS FOR THE STUDY OF CIVIC NETWORKS}

There is obviously little novelty in stressing the interdependent, networked nature of civic organizations. However, organizational interdependence may take multiple forms, and interorganizational networks may display a wide range of structures (Powell 1990). In order to understand collective action dynamics and organizational strategies, the simple consideration that civic organizations are "in touch with" each other is not sufficient. We need to reconstruct how interorganizational ties combine in complex structural patterns. In order to do so we can draw upon several bodies of literature-including community studies, interorganizational relations, and social movements. Analysts of community and policy networks have been among the few to apply network analysis to relations between political organizations (Laumann and Knoke 1987; Kenis and Schneider 1991; Knoke 2001). In contrast, most studies of political coalitions in- 
Civic Networks

volving participatory groups and associations have focused on the qualitative analysis of the logics accounting for actors' coalitional behavior rather than on the formal properties of those coalitions (e.g., Staggenborg 1986; Lichterman 1995; Rochon and Meyer 1997).

Even those scholars that actually mapped interorganizational relationships usually treated networks as systems of opportunities and constraints rather than as specific forms of social organization (Salancik 1995). On the one hand, economic and organizational sociologists have mostly focused on the consequences of certain network structures for organizational performance (Borgatti and Foster 2003). On the other hand, analysts of political processes have paid more attention to the antecedents of networks, interpreting the latter as the result of the more or less successful matching of organizational characteristics (Rosenthal et al. 1985; Ansell 2003; Osa 2003), or to the positional power held by actors occupying certain structural positions (Galaskiewicz 1989; Knoke 1990; Jones et al. 2001). Either way, they have rarely considered network structures worth investigation in their own right. In contrast, we argue that in order to understand their potential for collective action and social integration, civic networks have to be studied by looking at their overall properties and explained on the basis of the microlevel dynamics that generate certain macrolevel configurations (Lazega and Pattison 2001; Hedström 2005). To this purpose we identify two analytical dimensions: the network formal properties and the relational content of interorganizational ties.

\section{Network Formal Properties}

Civic networks may assume a range of forms. Studies of community leadership as well as of social movements point at two different network models, one hierarchical/centralized, the other more informal and polycentric. The contrast between these two forms has long characterized political sociology, starting with classic studies of community leadership, that either stressed the hierarchical and bureaucratic organization of elites or the pluralistic nature of power structures (Hunter 1953; Dahl 1961; Polsby 1960). Even more recent explorations that drew heavily on network analysis did not overcome the divide between a centralized, hierarchical view of interorganizational networks (Knoke and Rogers 1979) and a more complex, pluralistic, and issue-driven account of the structure of political influence in local communities (Laumann and Pappi 1976; Laumann, Galaskiewicz, and Marsden 1978).

Along similar lines, some scholars of social movements have stressed the importance of a formal, bureaucratic structure and clear division of labor in order to maximize movement outcomes and effective decision making (Gamson 1975; Zald and McCarthy 1987), while others have 


\section{American Journal of Sociology}

suggested a decentralized informal model to be the most effective, given the high adaptability and low vulnerability of a segmented structure to environmental changes (Lichterman 1995; Melucci 1996). Among them, Gerlach (2001) suggested a segmented, polycentric, and integrated structure-the so-called SPIN model - to be a powerful form of social movement organization, as it allows actors to prevent effective repression, penetrate into a variety of social niches through factionalism and schism, adapt to circumstances, and promote innovation. The few empirical studies of movements as social networks have not always generated consistent results: some have stressed the decentralized and multipolar nature of those networks (Sawer and Groves 1994), while others have shown movement networks to be highly centralized despite the informal nature of the ties linking movement actors to each other (Lowe and Goyder 1983; Diani 2003).

None of the contributions mentioned above, however, has proposed a formal account of the structure of political networks nor a systematic discussion of its properties. ${ }^{2}$ Figure 1 reports an ideal-typical representation of a hierarchical and a polycentric structure. The two structures have the same number of organizations (nodes), but they vary in the way in which organizations relate to each other. A hierarchical structure is characterized by one or few central organizations linked to a multiplicity of peripheral actors that are disconnected from each other. In contrast, a polycentric structure is characterized by multiple clusters of intense exchange among organizations, connected by few, sparse relations. ${ }^{3}$

Alternative network structures have a different impact on organizational strategies and collective action dynamics. At the macrolevel, they may affect the potential for large-scale mobilization and network robustness (here understood as the resistance to external threats), such as, for instance, the withdrawal of certain associations from the network; at the microlevel, they may influence the nature of organizational interdependence and the resulting power asymmetries and horizontal solidarity.

Let us consider the first two aspects. In hierarchical structures, core actors' attitudes and behavior may strongly affect the outcome of the

\footnotetext{
${ }^{2}$ In contrast, studies of economic networks have more systematically focused on the structural properties of interorganizational relations (Kenis and Knoke 2002; Kogut and Walker 2001; Powell et al. 2005).

${ }^{3}$ Locke refers to similar ideal-typical structures to account for the different ways in which local economies underwent the transformation and restructuring of the Italian economy. He argues that firms and unions embedded in polycentric sociopolitical networks were able to resolve conflicts through negotiations, whereas local actors involved in hierarchical sociopolitical networks were more dependent on top-down decision making and often negatively affected by the inertia of national authorities (Locke 1995).
} 

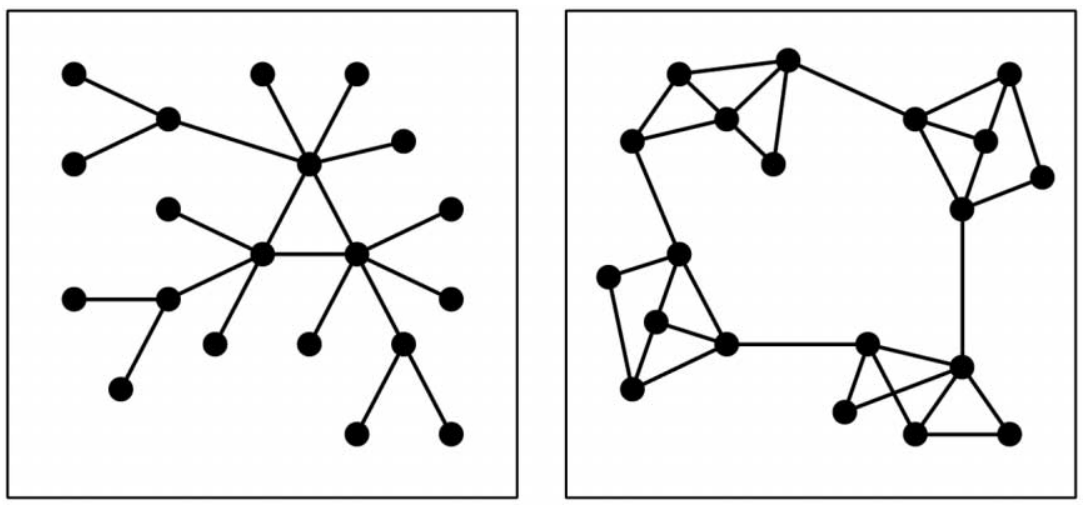

FIG. 1.-Ideal-typical network structures. Left: hierarchical structure; right: polycentric structure.

collective effort, for their power of control, influence, and therefore the potential for large-scale mobilization is high. At the same time, networks of this sort are particularly exposed to the impact of exogenous effects: if we remove from the network the core actors, whose commitment secures network cohesiveness, the entire network collapses. In contrast, polycentric structures consist of multiple, interconnected centers. In such configurations, power asymmetries are low. This means that while the mobilization of a small number of actors does not necessary trigger large-scale collective action, no single actors are really decisive for collective mobilization as well as for network cohesion. In fact, the overall network might be only marginally damaged by some actors' defection or disappearance (e.g., through repression: Gerlach and Hine [1970]). In sum, a hierarchical form of civic coordination has higher potential for large-scale mobilization, but it is less robust than a polycentric civic network.

Macrostructural properties imply certain microscale relational patterns. In our case, the distinction between hierarchical and polycentric structures is related, at the microlevel, to distinctive forms of organizational interdependence. Usually, interorganizational analysis focuses on forms of dependence asymmetry, that is, the "difference in actors' dependencies on each other in a dyadic exchange relationship" (Gulati and Sytch 2007, p. 32 ), and thus on issues of power and autonomy. However, organizational interdependence can also be characterized by forms of joint dependence and horizontal solidarity. For instance, alliance building among voluntary associations is difficult and possibly risky, raising issues of agenda control, choice of action repertoires, and compatibility of ideological perspectives (Staggenborg 1986; Jones et al. 2001; McCammon and Campbell 2002). For all these reasons, the choice of allies is a complex matter. For two 
organizations, being involved in alliances to the same third organization in the context of different projects may facilitate the start of a direct collaboration: consistent with the principles of balance theory (Cartwright and Harary 1956; Heider 1958), third parties may testify to two organizations' mutual reliability.

We therefore investigate patterns of organizational interdependence at the level of triadic interaction and differentiate between forms of asymmetric interdependence, based on asymmetric relations between specific pairs of actors and forms of balanced interdependence, in which reciprocity and transitive relations are at work. Only the latter have the potential to foster generalized reciprocity and sustain the horizontal solidarity that, since Tocqueville, has been regarded as distinctive of civil society. While asymmetric interdependence is typical of a hierarchical structure, balanced forms of interdependence are likely to induce a polycentric network structure.

To summarize, hierarchical civic networks can be very effective for the mobilization of actors but at the same time very sensitive to defections and/or external threats, and thus not robust. Moreover, hierarchical structures are based on relations of asymmetric interdependence that are not likely to induce horizontal solidarity and generalized exchange. In contrast, in polycentric structures, mobilization processes are more likely to depend on diffuse agreement among actors, which is costly, thus reducing effectiveness, but at the same time, they are less likely to be damaged by defections, therefore increasing robustness. Most important, microinteractions based on balanced dependence, instead of asymmetric dependence, are likely to foster dynamics of generalized reciprocity. Assessing whether real civic networks resemble a hierarchical or a polycentric structure is therefore useful in order to evaluate their level of potential mobilization, network robustness, and the nature of organizational interdependence.

\section{The Content of Network Ties}

While network formal properties are important, they cannot be fully understood without referring to the content of ties. As our analysis will show, it is by referring to the interplay between form and content of network ties that the peculiar structure of civic networks can be explained. Although analysts of interorganizational dynamics have often looked at content differentiation and tie multiplexity (Gould 1991; Knoke 2001; Kenis and Knoke 2002), they have devoted less attention to their composition and interplay. Empirical research tends to focus on ties of a specific kind and explore their function and strategic deployment. Among formal ties, interlocking directorates have attracted huge attention, being alternatively understood as systems of collusion, cooperation, control, or 


\section{Civic Networks}

social cohesion (Mizruchi 1996). But the effectiveness of interorganizational relations does not depend on formal ties only. Following Granovetter's argument on the social embeddedness of economic behavior (1985), several studies have underlined the role of personal relations and friendships between critical actors as means to generate mutual trust and reinforce social control (Lincoln, Gerlach, and Ahmadjian 1996; Walker, Kogut, and Shan 1997; Ingram and Roberts 2000).

Similar considerations about the contents of interorganizational relations also characterize studies of community structures and social movements. Laumann et al. (1978, p. 463) recognized two different kinds of relations as relevant to interorganizational networks: $(a)$ "linkages based on resources transfers," and $(b)$ linkages based on "interpenetration of organizational boundaries." Both types were considered as having a primarily instrumental basis, but "relations involving boundary interpenetration often have an additional component of solidarity maintenance (ibidem)." Social movement scholars have also paid attention to both aspects, recognizing the role of exchanges of resources, information, and personnel between organizations as well as that of the less visible, "latent" channels of communication represented by activists with multiple involvements in organizations and subcultural milieus (Zald and McCarthy 1987; Staggenborg 1986; Carroll and Ratner 1996; Diani 1995, 2003).

In general, organizations may restrict their interactions to the exchange of important resources for action, relevant political and technical information, or specific facilities (e.g., office space). Although such exchanges may create longer-term commitments and obligations, they also may end without further consequences once the specific initiative that prompted the coalition in the first place is over. Following Lémieux (1998, pp. 4750), we refer to these links as transactions, primarily driven by an instrumental logic. Alternatively, organizations involved in alliances and coalitions may be linked to each other by connections that imply deeper obligations and solidarities than those usually attached to short-term interactions. At the interorganizational level, examples of such ties are those reflected in multiple memberships and in individuals' participation in multiple activities promoted by different organizations. Particularly in organizations relying heavily —if not exclusively — on voluntary work, and therefore on their members' commitment, the sharing of activists by two or more organizations, or the presence of extensive personal links between them, may be regarded as an indicator of connections that are likely to go beyond the purely instrumental level. Interorganizational links generated through individual members' choices and connections may be regarded as social bonds (Lémieux 1998, pp. 45-47), reflecting a logic of belongingness.

Arguments related to links multiplexity are usually deployed when ac- 
American Journal of Sociology

counting for individual and organizational strategies, for asymmetries in actors' social influence, or in order to assess the function, quality, stability, and strength of social relations. For instance, referring to a classical example, the robustness of Medici's action and the multivocality (ambiguity) of their behavior mainly relied on the heterogeneity of their links-marriage, economic, and patronage relations-and the cross-cutting networks these generated (Padgett and Ansell 1993). However, the nature and multiplexity of social relations are not merely properties enabling or constraining actors. They may also play a role in shaping the network structure. It is this latter aspect that attracts our attention. More specifically, we focus on the distribution of instrumental and affective ties across the network, and we expect these ties to be responsible for civil society's micro- and macrointegration.

In general, macro- and microintegration are supposed to have different bases. According to the most common view, microlevel integration within cohesive groups is fostered by strong ties, while macrolevel integration depends on weak ties that extend beyond groups (Granovetter 1973, 1983; Blau 1974; Friedkin 1980). Namely, strong ties constitute a base for solidarity and trust within primary groups, providing sustain in situations of change and uncertainty (Krackhardt 1992), while weak ties reach out beyond primary groups, favoring the circulation of information and resources (Granovetter 1973, 1983). Transactions and social bonds can be seen as a particular case of the broader distinction between weak and strong ties, yet with an important qualification: while the original conceptualization sees the strength of a tie as the combination of frequency of interaction and both emotional and practical contents of the relation (Granovetter 1973, p. 1361), in our case, the variation in the strength of a tie consists of the qualitative difference between instrumental and affective relationships.

In their reassessment of data from classical community studies of the 1970s (Laumann and Pappi 1976), Breiger and Pattison (1978, pp. 22224) found social ties between community leaders to be stronger than instrumental business-professional ties. Extending this argument to the organizational level, we expect that social bonds characterize clusters of dense interaction between relatively similar organizations, while transactions play the role of weak ties that bridge different groups and increase the overall interconnection of civic networks.

According to this view, social bonds and transactions entail two opposite relational tendencies: an in-group orientation that reinforces identities and solidarity within certain collectivities and a bridging tendency that links different groups and generates broader, encompassing identities. In the extreme cases, a strong predominance of social bonds would end up fragmenting the network into diverse groups of noncommunicating actors, 


\section{Civic Networks}

while a civic network prevalently characterized by transactions would reflect a random pattern of relations between individual organizations. We expect real civic networks to lie somewhere in between these two extreme models, emerging from a balance between transactions and social bonds. We do not conceive these tendencies as alternative, and we expect civil society associations to be involved in both types of relationships. Burt convincingly maintains the complementary role of brokerage and closure in bringing about social structures capable of enhancing the social capital of their members (Burt 2005). Here, we build on his contribution, showing how the simultaneity of brokerage and closure is made possible by the interplay between different kinds of relationships. ${ }^{4}$

\section{THE STUDY AND ITS CONTEXT}

\section{Research Design and Data}

The data used in this article were collected in the context of a broader project on networking by citizens' organizations in local settings in Britain. We concentrated on urban areas such as Glasgow and Bristol because of the density and complexity of their associational life and because cities are, to some extent, more self-contained than other settings (which makes it somewhat easier to draw population boundaries). We selected a time period that was mainly characterized by ordinary forms of collective action in order to maximize aspects of regularity in interorganizational dynamics. Finally, we surveyed two cities that differ with respect to their social and political profile, in order to consider the impact of the political context on civic network configurations.

Our study focused on participatory organizations promoting advocacy and interest representation on a broad range of public issues. We excluded from our sample organizations focusing exclusively on service delivery, while we included organizations whose main focus was in that area as long as they would engage at least in some type of political pressure. In principle, it would have been desirable to map the whole set of organizations promoting collective action on public issues, whether on a service delivery or a protest-oriented basis. However, resource limitations and the need to conduct costly face-to-face interviews, given the complexity of data collection on networks, forced us to concentrate on organizations active on a smaller set of issues. Altogether we collected data for 124 organizations in Glasgow and 134 in Bristol, whose main focus was evenly

\footnotetext{
${ }^{4}$ In a more discursive vein, Putnam distinguishes between "bonding" and "bridging social capital" as two complementary, but distinct, forms of social capital that are based respectively on strong and weak ties (Putnam 1993, 2000).
} 
American Journal of Sociology

distributed among environmental issues, ethnic and migration issues, community issues, and social exclusion issues, but for a slight overrepresentation of environmental groups in Bristol and ethnic and migrants' groups in Glasgow (table 1).

Environmental issues included both classic conservation themes, as represented by organizations like the Royal Society for the Protection of Birds, and urban ecology issues, as exemplified by the agenda of groups like the Bristol Cycling Campaign or JAM74, a coalition opposing the extension of the motorway 74 in Glasgow (not to mention nationwide organizations such as Friends of the Earth or Greenpeace). Ethnic and migration issues covered both a broad agenda on multiculturalism, equal opportunities, citizenship rights, and minority members' access to educational and welfare provisions, and a more specific agenda promoting migration-relatedin particular, asylum seekers'-interests. These were the target of initiatives promoted by organizations acting on behalf of specific communities-most notably, the Pakistani, Indian, and Afro-Caribbean communities - and by broader coalitions such as the Glasgow Welcomes Refugees Campaign or the Bristol Defends Asylum Seekers Campaign. Community issues included a whole range of themes related to the welfare of local communities and neighborhoods, from community development to the quality of service provision to local crime. Once again they were acted upon by a broad range of actors ranging from neighborhood associations such as the Easton Community Centre in Bristol or the Govan Community Organization in Glasgow to single-issue campaigns, such as the initiatives opposing the sale of Glasgow council housing on the private market. Finally, social exclusion issues included all aspects of social inequality, from unemployment to education to poverty, addressed both at the local and at the national—or even global-level. They were taken up by a highly heterogeneous set of organizations, from voluntary associations focusing on capacity building in the community-for example, the Poverty Alliance in Glasgow - to direct action groups and coalitions such as the Bristol Housing Action Movement or Globalize Resistance.

We chose to focus on these four main issues because they were distinctive enough to be the object of specific action by specific organizations, while being at the same time amenable to attempts to merge them in broader and more encompassing agendas. For a study aiming at reconstructing network practices, it was important to look at issues that neither forced citizens' organizations to collaborate, given the almost entire overlap between them, nor kept them apart due to their incompatibility. For example, while a lot of-possibly, most—actions on environmental issues could be promoted by coalitions involving primarily environmental groups-or even specific organizations trying to acquire "ownership" of a specific issue - this was by no means necessary. They might have been 
Civic Networks

TABLE 1

Organizational Characteristics in Bristol and Glasgow

\begin{tabular}{|c|c|c|}
\hline Variable Description & Bristol $(N=134 ; \%)$ & Glasgow $(N=124 ; \%)$ \\
\hline \multicolumn{3}{|l|}{ Most important issue: } \\
\hline Environment ....... & 27 & 16 \\
\hline Ethnic minorities and mi- & & \\
\hline grants $\ldots \ldots \ldots \ldots \ldots \ldots$ & 19 & 28 \\
\hline Community $\ldots \ldots \ldots \ldots \ldots$ & 28 & 23 \\
\hline Social exclusion $\ldots \ldots \ldots \ldots$ & 25 & 33 \\
\hline \multicolumn{3}{|l|}{ Scale of activity: } \\
\hline Neighborhood & 27 & 27 \\
\hline Citywide $\ldots \ldots \ldots \ldots \ldots \ldots$ & 40 & 32 \\
\hline Regional $\ldots \ldots \ldots \ldots \ldots \ldots \ldots$ & 18 & 21 \\
\hline National or transnational ... & 15 & 20 \\
\hline \multicolumn{3}{|l|}{ Years of activity in 2002 : } \\
\hline $1-5 \quad \ldots \ldots \ldots \ldots \ldots \ldots \ldots \ldots$ & 24 & 32 \\
\hline $6-10 \quad \ldots \ldots \ldots \ldots \ldots \ldots \ldots \ldots$ & 21 & 15 \\
\hline $11-20 \ldots \ldots \ldots \ldots \ldots \ldots \ldots$ & 34 & 24 \\
\hline$>20 \quad \ldots \ldots \ldots \ldots \ldots \ldots \ldots \ldots$ & 21 & 29 \\
\hline \multicolumn{3}{|l|}{ No. of registered members: } \\
\hline $0 \quad \ldots \ldots \ldots \ldots \ldots \ldots \ldots \ldots \ldots$ & 27 & 44 \\
\hline $1-1,000 \ldots \ldots \ldots \ldots \ldots \ldots \ldots$ & 62 & 44 \\
\hline$>1,000 \ldots \ldots \ldots \ldots \ldots \ldots \ldots$ & 11 & 12 \\
\hline \multicolumn{3}{|l|}{$\begin{array}{l}\text { No. of paid staff members } \\
\text { (full- and part-time): }\end{array}$} \\
\hline $0 \quad \ldots \ldots \ldots \ldots \ldots \ldots \ldots \ldots \ldots \ldots \ldots \ldots \ldots$ & 30 & 35 \\
\hline $1-5 \quad \ldots \ldots \ldots \ldots \ldots \ldots \ldots \ldots$ & 22 & 35 \\
\hline 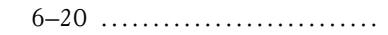 & 36 & 16 \\
\hline$>20 \ldots \ldots \ldots \ldots \ldots \ldots \ldots \ldots$ & 12 & 14 \\
\hline \multicolumn{3}{|l|}{ Budget: } \\
\hline None $\ldots \ldots \ldots \ldots \ldots \ldots \ldots$ & 4 & 7 \\
\hline Under $£ 10,000 \quad \ldots \ldots \ldots \ldots \ldots$ & 26 & 24 \\
\hline$£ 10,000-£ 99,999 \ldots \ldots \ldots \ldots$ & 26 & 35 \\
\hline Over $£ 100,000 \ldots \ldots \ldots \ldots$ & 44 & 34 \\
\hline \multicolumn{3}{|l|}{ Level of formalization: ${ }^{a}$} \\
\hline Low $(0-3) \ldots \ldots \ldots \ldots$ & 25 & 21 \\
\hline Medium $(4-6) \quad \ldots \ldots \ldots \ldots \ldots$ & 55 & 43 \\
\hline High $(7-9) \ldots \ldots \ldots \ldots \ldots$ & 20 & 36 \\
\hline
\end{tabular}

${ }^{a}$ Additive index based on nine indicators: chairperson, board of directors, executive and/or special committee, secretary, treasurer, written constitution, general assembly, charity status.

as plausibly promoted-in fact, in many cases they were promoted-by coalitions involving other types of actors, such as community groups, or organizations fighting social exclusion from an "environmental justice perspective." Likewise, it is easy to think of, and to record in reality, examples of collaborations between groups linking ethnic minority issues to global environmental ones, or linking social exclusion at the local and the global level with opposition to war and support of human rights. 


\section{American Journal of Sociology}

While nothing prevented the organizations we studied from acting mainly as independent organizations on their own specialized ground, or within the boundaries of narrowly defined organizational fields, it was similarly possible for them to bridge their own issue priorities in broader agendas more similar to those promoted by large-scale coalitions and, possibly, social movements.

In order to identify our unit of analysis, we started from the directories of organizations generated by the umbrella organizations operating as service providers to the voluntary and community sector in the two cities, GCVS (Glasgow Council for the Voluntary Sector) and Voscur (Bristol's Voluntary Organisations Standing Conference on Urban Regeneration). We supplemented the information collected through those sources with data from a limited number of informants, either representatives of the main umbrella organizations and of related bodies such as the Bristol Racial Equality Council or the Glasgow Minority Network, or academics with specific research experience in the local scene. We included all the organizations that, according to our informants, played a significant role at least at the city level (for an example of case selection based on reputation see Laumann and Knoke [1987]). As for community organizations, rather than taking a small sample from across the city, efforts were concentrated on two areas, both relatively deprived. These were the Southside in Glasgow, an area with a massive historical presence of the working class, and which included neighborhoods such as Govan, Govanhill, Gorbals, and Pollokshields; and the area including the neighborhoods of Easton, Knowles, Withywood, and Hartcliffe in Bristol, featuring a strong presence of ethnic minorities. If, during the interviews, other organizations not included in our original list were named as important allies by our respondents, they were noted and interviewed after at least three references had been made. ${ }^{5}$

Data were collected between 2001 and 2002 through face-to-face interviews with organization representatives. These would normally be the contact people listed in the local directories or, when this information was unavailable, indicated by our informants or interviewees. We made sure that our interviewees were familiar with the life of their organization in the previous years-a possible problem, particularly with professional staff. Interviews normally lasted between one and two hours and were based on a questionnaire consisting largely of a predetermined list of items,

\footnotetext{
${ }^{5}$ We have strong reasons to believe that with the exception of one ethnic organization in Bristol, all the most central organizations in the two cities were contacted; while many organizations were mentioned by respondents (over 500 in both cities), none received more than three nominations.
} 


\section{Civic Networks}

plus a smaller number of open questions. ${ }^{6}$ Only one interview was refused, by a Bristolian group that was central in the ethnic and migrants network but was going through a serious-if temporary—organizational crisis.

The organizations we interviewed differed substantially on a number of organizational indicators (table 1):

1. About one-quarter of them had been established in the last five years, while a similar share had been in operation for over 20 years (some of them actually dating back to the late 19th century).

2. About one-quarter focused on specific neighborhoods, while four in ten operated mainly at the city level, and the rest combined local action with action at the national or transnational level.

3. A proportion ranging from one-third in Bristol to almost half in Glasgow had no formal membership, while about one in ten had a local membership exceeding 1,000 .

4. About one-third had yearly budgets below $£ 10,000$ and could not count on any paid staff, not even on a part-time basis, while about one-tenth had budgets exceeding $£ 100,000$ and more than 20 staffers.

5. About one-quarter scored very low on a nine-point scale of organizational formalization, while another quarter was highly formalized.

Respondents were asked to name up to five most important allies on the basis of the following question: "Please list up to five groups/organizations with which you collaborate most intensely." While they were not submitted any predetermined list as a stimulus, later in the interview they were also asked whether, on top of the five partners already mentioned, they had any connection to organizations in any of the following types: environmental groups, ethnic minority and migrant organizations, community organizations, unions and other economic interest groups, religious organizations, political parties, other political organizations, other voluntary associations, or any other organization. Participation in a formally constituted organization, coordinating a number of different groups on a specific campaign, was recorded as an interorganizational tie, similar to an alliance between two any other formally independent organizations.

We also urged respondents to specify the content of the link, in order to qualify the nature of the tie. Specifically, we asked whether the tie implied (1) the conducting of joint projects, (2) the sharing of information, (3) the pooling of resources, ${ }^{7}$ (4) the sharing of core members, or (5) the

${ }^{6}$ Questionnaire available from the authors.

${ }^{7}$ While the conducting of joint projects implies shared information and resources, the reverse does not necessarily apply. Organizations may also collaborate through regular exchanges of information, or through the pooling of resources (a classic example being sharing offices). 


\section{American Journal of Sociology}

presence of activists with strong personal ties to each other. We operationalized transactions as those links that only consist of exchanges of resources, as measured by tie types 1-3. In contrast, social bonds are multiplex links which can be seen as the composition of "transactions" and "personal ties," measured by ties $4-5$. The latter links clearly imply actors stressing the elements common to them in a logic of collective membership to a group, however defined. ${ }^{8}$ We did not measure the intensity of the ties, but merely their presence or absence, as it has been repeatedly shown that respondents' accuracy in recording the presence of ties is not usually matched by a similar accuracy in reporting about its intensity (Marsden 1990). Moreover, we were most interested in identifying the alliances that each organization regarded as most important, rather than in contrasting intensity or frequency of interaction, which is by definition strongly dependent on other factors such as organizations' overall centrality or size. ${ }^{9}$

\section{Socioeconomic and Political Context}

Bristol and Glasgow share some basic social and political traits. They have both experienced a drastic move from an industrial to a servicebased economy. Since the closure of the docks and most of the heavy industry in the 1960s-70s, working-class presence in both cities has been increasingly modest, with employment in the manufacturing industry in the early 2000s accounting for about $10 \%$ of the workforce in Glasgow and $11 \%$ in Bristol. ${ }^{10}$ In political terms, they have both experienced the increase in opportunities for formal institutional access brought about by New Labour since the late 1990s, the trends toward the professionalization of the voluntary sector, and its growing involvement in policy design and implementation, usually in partnerships with business and local government (Lowndes, Pratchett, and Stoker 2001; Taylor 2003). However, differences outweigh analogies by far.

With respect to the occupational structure and welfare, Bristol has a

\footnotetext{
${ }^{8}$ In principle one could also conceive of situations in which organizations are involved in the same sub- or countercultural milieus, organizational industries, or movement sectors through the multiple forms of participation and the personal connections of their members (ties of the type 4-5), yet are not engaged in any type of resource exchange (Melucci 1996; Taylor and Whittier 1992). Given the focus of this study on civic, public-oriented collective action, those ties are not considered here.

${ }^{9}$ For example, one monthly meeting between a neighborhood environmental group and a major environmental association may be a strong tie for the former but a weak tie for the latter.

${ }^{10}$ The local statistics reported in this article are from the 2001 UK Census and are available at http://www.statistics.gov.uk/Census2001. In 2001, Bristol counted 380,000 residents, Glasgow, 630,000.
} 
strong presence of professional bourgeoisie and highly qualified white collar workers, even though areas of relative deprivation undoubtedly exist, some of which are included in this study. Its main employers are high-tech firms like those in the aeronautic industry, firms in the service sector, especially the financial sector, and big public employers such as the ministry of defense. This is reflected in a population with a higher proportion of degree holders and professionals/managers than in Glasgow ( $25 \%$ vs. $18 \%$ and $28 \%$ vs. $21 \%$, respectively). Bristol is also significantly more affluent than Glasgow. At the start of the new millennium, unemployment rates were substantially higher in Glasgow than in Bristol $5 \%$ vs. 3\%), with long-term unemployment in particular representing a major problem ( $37 \%$ of the unemployed vs. $25 \%$ in Bristol). Housing was another major issue, with $39 \%$ of the population still living in council flats (vs. $21 \%$ in Bristol) and $17 \%$ living in homes with no central heating (vs. 9\%).

The ethnic scene is also larger and more diversified in Bristol. Over $8 \%$ of the 2001 residents were born outside the United Kingdom, with some neighborhoods approaching $20 \%$ of minority residents, versus $5 \%$ in Glasgow. Both the Asian and black (mostly Afro-Caribbean) communities are well represented (2.8\% and $2.3 \%$, respectively). In contrast, black communities are hardly present in Glasgow, while Pakistanis are the dominant minority group, outnumbering the Indians and the Chinese by two to one.

These differences translate in what are in many ways two different political cultures. Despite the conversion of Glasgow toward a more diversified and more service-driven economy, the persisting levels of deprivation in some areas maintain a huge potential for collective action addressing social inequality and related issues. This has facilitated the continuing central role in local politics of working-class and left-wing labor politics, while the strength of the Pakistani community vis à vis other minority groups has also encouraged and reproduced their integration in the Labour political machine. One should also remember the role of the center-periphery (Nationalist) cleavage and the religious (Protestant vs. Catholic) cleavage in fostering a polarized political culture.

City politics in Bristol have also been dominated by Labour since the 1980s (at least until the May 2003 local elections), but the overall profile of the city is very different, with a history of swings between Labour and Tories in the context of an overall moderate political culture. Pooled data for the two cities from the four waves of the British Social Attitudes survey, covering the years in which this project was conducted (20002003), well illustrate differences in the role of Labour relative to other political parties. While the share of Labour sympathizers is fairly similar (50\% in Glasgow as opposed to $46 \%$ in Bristol), the ratio of Labour supporters to supporters of other major parties is drastically different in 
American Journal of Sociology

the two cases: they outnumber Conservative supporters by fourteen to one in Glasgow and by two to one in Bristol, and Liberal-Democrat supporters by ten to one in Glasgow and by four to one in Bristol. While Glasgow has been a stronghold of left-wing political groupings critical of the Labour party (the latest and most successful being the Scottish Socialist Party), similar groups have never achieved organizational strength in Bristol despite a small, very active community of radical activists independent from any formal organization. A distinctive trait of Bristol civic culture is what one of the activists interviewed for this project described as a "laid-back political culture," that is, a style of politics in which radical polarization along major class divides comes second to the concerted attempts to mediate between multiple interests. Even the impact of the new social movements in Bristol has mostly been at the cultural level. The city has been one of the main centers for cultural innovation, with a flourishing milieu of youth subcultures and alternative lifestyles addressing issues of health, alternative food, and body care (Purdue et al. 1997).

We checked if the greater perceived salience of the left-right, classbased cleavage in Glasgow also emerged from patterns of interorganizational alliances; if, in other words, organizations tended to interact with organizations with the same political affiliation. To this purpose we run categorical autocorrelations based on a model of variable homophily (Borgatti, Everett, and Freeman 2002) in order to test the hypothesis that organizations affiliated with the Labour Party and other leftist parties were more likely to engage in alliances among themselves than with other organizations. Homophily coefficients turned out to be larger in Glasgow than in Bristol (.043 vs. .017), and the model was statistically significant only in the former, to confirm the persistent salience of the class cleavage in Glasgow, and its limited relevance in Bristol.

\section{RESULTS}

Hierarchical versus Polycentric Network Structures

Our first analytical dimension differentiates at the macrolevel between hierarchical and polycentric structures, and at the microlevel between asymmetric and balanced forms of interorganizational interdependence. Let us start by looking at four graph-level measures that describe the macrolevel features of civic networks. Two of these measures-hierarchy and connectedness-evaluate the proximity of civic networks to hierarchical structures (Krackhardt 1994). Instead, the view of civic networks as polycentric structures is related to two characteristic measures of smallworld graphs—clustering and average path length (Watts 1999). Krack- 


\section{Civic Networks}

hardt's graph hierarchy assesses the degree of asymmetry in relations among organizations, based on the assumption that in an ideal hierarchical structure, relations are completely asymmetric. ${ }^{11}$ Graph hierarchy is a function of "the fraction of connected pairs that are asymmetric in their ability to reach one another" (Anderson, Butts, and Carley 1999, p. 240). While graph hierarchy captures the overall level of asymmetry in relational patterns, connectedness catches the overall level of connectivity among actors. ${ }^{12}$ Connectedness is defined as the fraction of all the pairs that are not disconnected. In a pure hierarchical structure, connectedness is one, because all the organizations are linked to higher-level units and, ultimately, to the organization at the highest level. In a nonhierarchical structure, instead, organizations do not necessarily refer to the same head unit and therefore might be disconnected from each other.

In contrast, a polycentric structure can be approximated by small-world graphs, which are characterized by clusters of dense interaction loosely linked to each other (Watts 1999). Distinctive of small-world graphs is the fact that the presence of few links that span across different areas of local interaction determines high levels of network connectivity despite the segmented and polycentric nature of the network. Relevant measures are clustering coefficient and average path length. The clustering coefficient of an actor can be thought of as a measure of the cliquishness of the actor's network, and it refers to "the degree to which a person's acquaintances are acquainted with each other" (Watts 1999, p. 33). In our context, it captures the extent to which civic organizations are embedded in highly dense clusters of interaction. ${ }^{13}$ While the clustering coefficient measures the level of organizational embeddedness in dense clusters of exchange, the average path length (or mean geodesic distance) is a global measure of separation that captures the level of interconnection among different clusters by looking at the overall reachability between organi-

\footnotetext{
${ }^{11}$ Krackhardt's degree of hierarchy is defined as graph hierarchy $=1-[$ V/MaxV $]$, where $V$ is the number of unordered pairs of points that are symmetrically linked (A is linked to $\mathrm{B}$ and $\mathrm{B}$ is linked to $\mathrm{A}$ ), and Max $V$ is the number of unordered pairs of points that are asymmetrically linked (A is linked to B or B is linked to A) (Krackhardt 1994, p. 97).

${ }^{12}$ Connectedness is defined as connectedness $\left.=1-[V / N(N-1) / 2)\right]$, which is the total number of mutually reachable pairs divided by the maximum number of possible pair combinations (Krackhardt 1994, p. 96).

${ }^{13}$ Technically, the clustering coefficient of an actor refers to the density of its open neighborhood. Defining a neighborhood of actor A as the subgroup of actors that are connected with $\mathrm{A}$, the clustering coefficient is the probability that two members of such neighborhood will be connected. A graph-level measure of clustering is then computed as the mean of the clustering coefficients for all the actors.
} 
American Journal of Sociology

zations. ${ }^{14}$ In general, random graphs have short path lengths, for there are no preferential rules in determining connections. In contrast, social networks usually show longer paths than random graphs, as social interactions do not reflect randomness but various criteria of social segmentation.

Interestingly, the two ideal-typical network structures considered herethe hierarchical and the polycentric-do not necessarily show opposite features with respect to the measures considered. While hierarchy and clustering are respectively high and low in a hierarchical structure, and low and high in a polycentric one, high connectedness and reachability (which means short average path length) might be observed in both structures, but for different reasons. In highly centralized networks, short distances between nodes are due to the presence of one or a few central nodes, to which almost all the other nodes are connected. In a small world structure, instead, connectivity properties are due to a few links that connect widely separated parts of the graph. Of course, actual measures of hierarchy and clustering will allow us to assess which connectivity mechanism is in place.

We compared Glasgow and Bristol civic networks with simulated random graphs that retain the same size and degree distribution of the observed networks. Random networks of this sort resemble a scenario in which organizations do not have any specific preference in choosing their alliance partners. Differences between observed and simulated networks are interpreted as the outcome of specific dynamics of interaction. This analytic strategy (previously used by Bearman, Moody, and Stovel [2004]) not only provides a criterion for the evaluation of observed networks, it also allows us to compare the two cities with respect to their structural characteristics, notwithstanding their differences in network size and density. Substantively, this means to compare our observed civic networks with the networks that would emerge from the same population of organizations if their patterns of interaction were not affected by any specific criteria in the choice of their allies. Of course, we expect social networks to be different from random ones. How they differ is the issue at stake here.

We drew 1,000 simulations from the observed degree distribution and computed the four measures of interest for each simulated graph. Simulated networks provide a distribution of values with which the observed value index is contrasted. Box plots in figure 2 show the distribution of simulated graphs across measures of hierarchy, connectedness, average path length, and clustering coefficient. The whiskers extend to the most

${ }^{14}$ Technically, it is the mean distance among reachable pairs and is computed as the mean of the shortest geodesic distance for each connected pair. 
Civic Networks
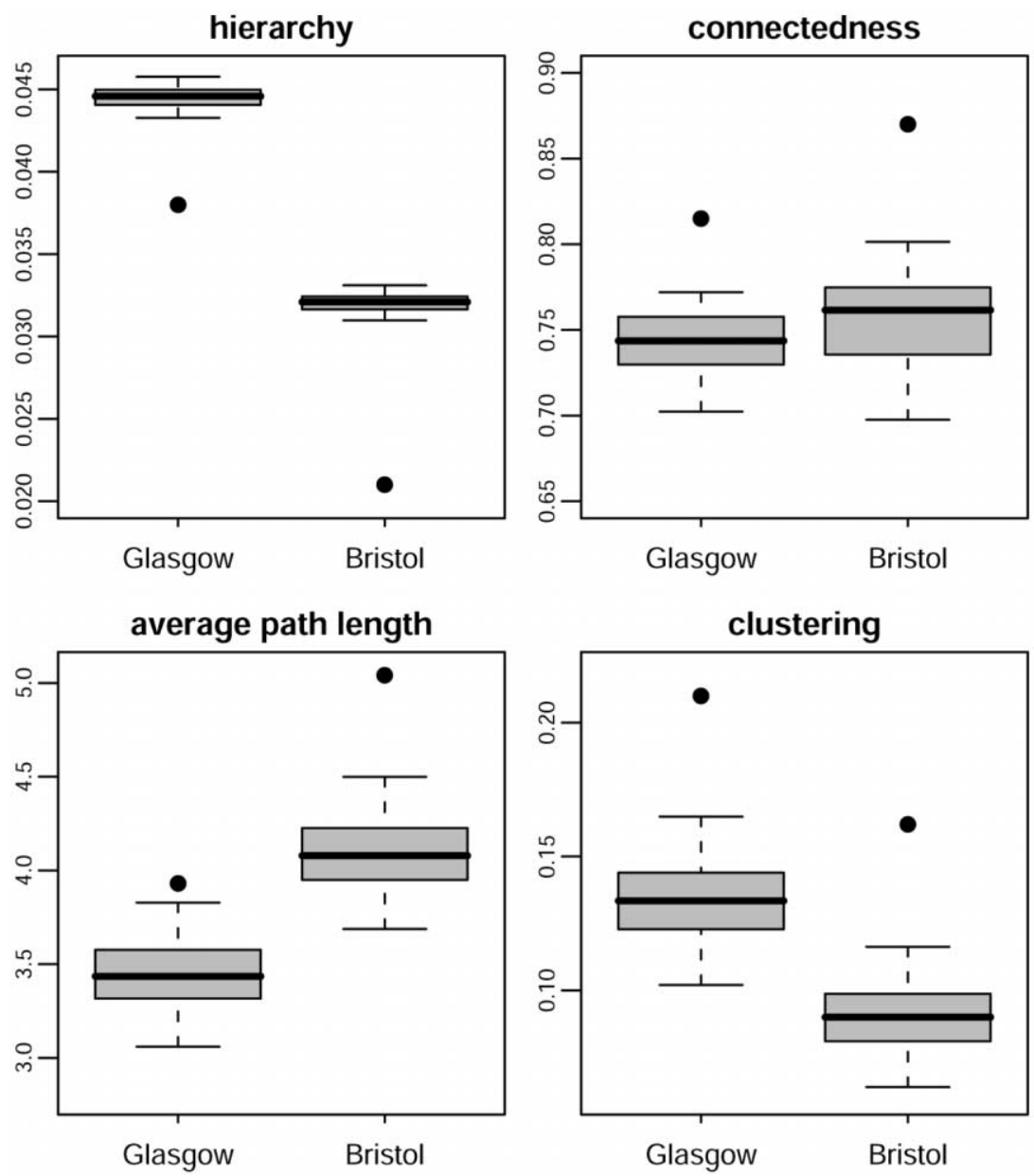

FIG. 2.-Graph measures of hierarchical and polycentric structures. For each of the four structural measures of interest (hierarchy, connectedness, average path length, and clustering), the plot compares values for observed networks (dots) to the distribution of values obtained from 1,000 simulated random graphs with preserved degree distribution (box plots). Whiskers extend to the most extreme datapoint that is no more than 1.5 times the interquartile range from the box. Glasgow and Bristol.

extreme data point that is no more than 1.5 times the interquartile range from the box. Dots indicate the actual value for Glasgow and Bristol.

A first, nontrivial result concerns the similarities between the two cities. When contrasted with simulated graphs, both Glasgow and Bristol show the same structural properties: dark dots are positioned exactly in the same way with respect to the box plots. Moreover, results are fairly clear 


\section{American Journal of Sociology}

with respect to which alternative structure civic networks resemble. In fact, observed networks show lower levels of graph hierarchy than expected by chance, while they have significantly higher levels of clustering. This means that civic organizations are involved in nonhierarchical patterns of exchange and tend to create areas of dense interaction; interorganizational collaboration takes place within clusters of intense activity, in which common partners contribute to the creation and maintenance of a reliable environment.

Both measures of connectivity are higher than expected by chance, but, as we know, their interpretation can vary. Although hierarchical structures are expected to show high levels of connectedness, the very same property also characterizes polycentric structures. Given the low graph hierarchy here observed, connectedness is not related to the role of few central actors but to the spanning capability of polycentric structures. At the same time, observed civic networks do not fully resemble small-world graphs, for the reason that the average path length is still longer than expected by chance, if more pronouncedly in Bristol than in Glasgow. This further suggests the presence of some degree of segmentation in both civic networks.

Overall, the Glasgow and Bristol civic networks are decentralized, polycentric models of interorganizational relations in which a tendency to form clusters of dense interaction and exchange couples with the presence of links between clusters that facilitate general network connectivity. As previously discussed, in a polycentric network, coordinated action is more likely to depend on the diffuse agreement among actors, and its overall stability is unlikely to be threatened by few defections. Moreover, we expect polycentric structures to be based on microinteractions of balanced interdependence. Further evidence on this comes from the analysis of microlevel patterns of interorganizational alliances.

\section{Asymmetric versus Balanced Interdependence}

A common approach to the study of micropatterns of relation is by looking at triadic interactions. As previously discussed, organizational interdependence might rely on asymmetric or balanced relationships. Asymmetric interdependence is reflected in patterns of microinteraction characterized by unidirectional relations, most particularly in the so-called star triadsinteractions in which one organization plays a pivotal role in connecting other organizations. They are typical features of hierarchical structures and are likely to reflect ad hoc exchanges, mostly driven by instrumental calculations. In turn, balanced interdependence is captured by microlevel exchanges that take the form of mutual and transitive triads and bring 


\section{Civic Networks}

about polycentric or, more generally, small world structures (Robins, Pattison, and Woolcock 2005).

Given three organizations (nodes) and assuming directed links between them, we can observe in any given network up to 16 triadic configurations. Triads are classified accordingly (see table 2). Here, in addition to asymmetric and balanced, we consider mixed triads as those triads combining both asymmetric and balanced ties. Each triadic configuration represents a scheme of interactions that is more or less likely to happen, or that can simply occur by chance. We contrast the number of observed triads with the triad distribution of 1,000 random graphs with preserved degree distribution. Each triadic configuration is considered overrepresented if the number of observed triads is higher than the value obtained in more than $95 \%$ of simulated graphs; it is underrepresented if the number of triads is lower than the value observed in more than $95 \%$ of simulated graphs. Otherwise, we conclude that a triadic configuration does not significantly differ from what can be observed by chance. Table 2 reports the triads that are significantly under- or overrepresented in either city, differentiating triads according to three forms of organizational interdependence: asymmetric, balanced, and mixed.

The strong similarity between the two civic networks is evident even at a glance. With the exception of two triadic configurations that are nonsignificant in Glasgow but significant in Bristol, all the other configurations are over- or underrepresented in the same way and with comparable magnitude. ${ }^{15}$ Thus, despite the historical and social differences that characterize the two cities and their collective experiences, interorganizational collaborations are built upon the same skeleton.

Substantively, we find that those triads that are expressions of asymmetric interdependence are systematically underrepresented, while instances of balanced interdependence largely prevail. Three aspects deserve to be highlighted here, starting with the tendency toward reciprocity, characteristic of a large variety of social networks. As it can be observed, overrepresented triads all show dynamics of interaction that involve at least one reciprocated tie. A second relevant aspect concerns the diffusion of triangles and "cliquing triads" (triads with a large number or even all the possible links), which are indicators of balanced interdependence. Interorganizational relations are more likely to unfold in dense subgroups of interaction rather than among almost disconnected actors. Different from a hierarchical structure, where intense exchanges among few major organizations combine with a large periphery of organizations, discon-

${ }^{15}$ Strong similarities between the structure of the two networks are also observable computing $p^{*}$ models (exponential random graph Markov chains, order 3 ) that account for the network structure considering third-order interaction effects. 
American Journal of Sociology

TABLE 2

Asymmetric and Balanced Forms of Triadic Interaction

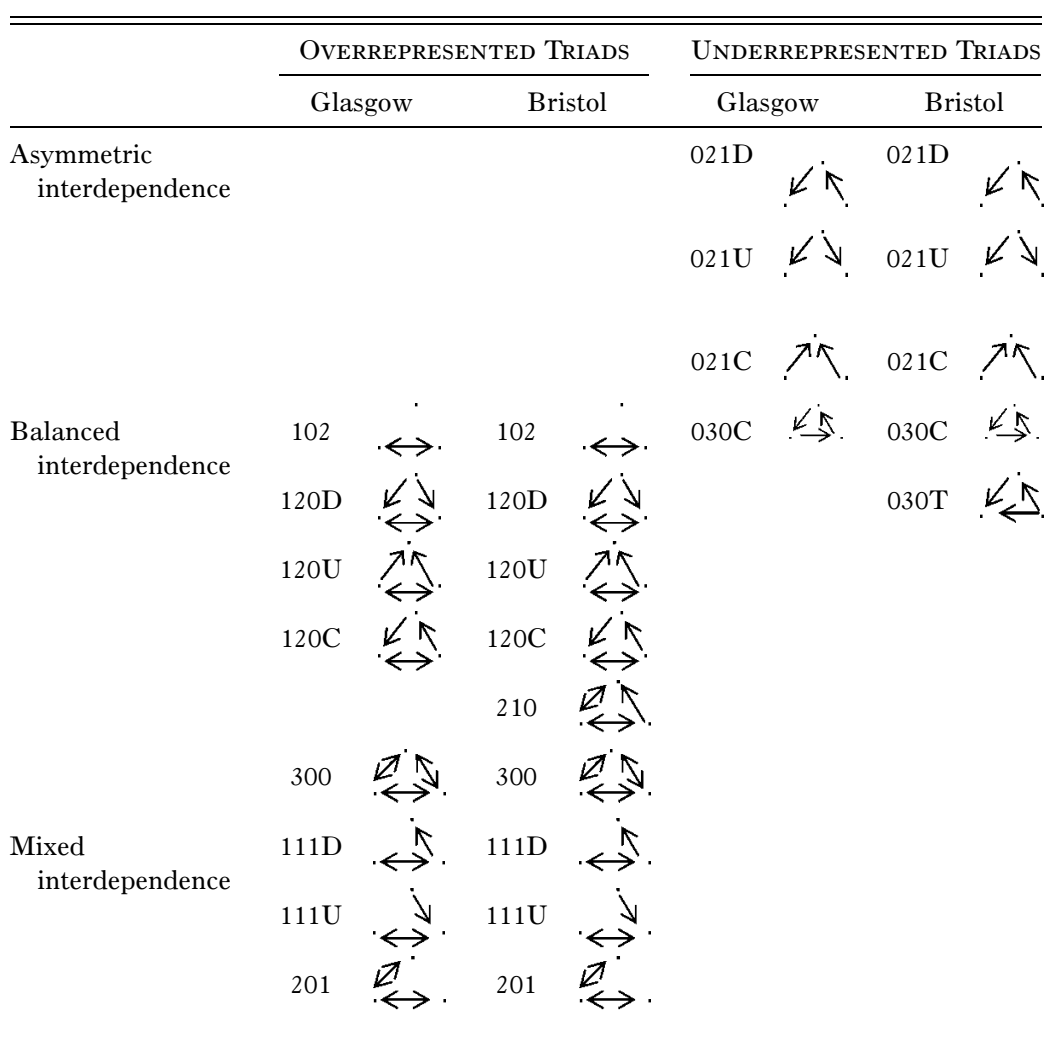

NotE. - The table reports triads that are over- or underrepresented in $95 \%$ or more of the cases compared to the distribution of 1,000 simulated random graphs with fixed-degree distribution. Glasgow and Bristol.

nected from each other and poorly connected to the core members, we observe a lack of sparse relationships in favor of dense patterns of exchange. This is ultimately established by a third relevant aspect of civic networks, namely, the scarcity of two-star triads, indicators of asymmetric dependence and consequently of hierarchical structure. There is only one instance in which two-star triples are overrepresented: in mixed form of interdependence when combined with mutual triples. While a two-star pattern of interaction suggests an asymmetric relation, a mutual tie represents an alternative tendency toward reciprocity, which naturally lessens the meaning of asymmetric relations.

Consistent with the findings at the macrolevel, Glasgow and Bristol civic networks are centered on dynamics of balanced interdependence. A 


\section{Civic Networks}

logic of embeddedness, mutual recognition, and joint action prevails over a logic of power and asymmetric exchanges. As previously discussed, these microlevel dynamics are the building blocks of generalized reciprocity in which the meaning of the exchange extends to third actors and thus aliments forms of horizontal solidarity.

Our next task is to explain how this model of polycentric coordination is generated through local interactions. One fruitful way to deal with the question is to understand network properties as a "macro implication of one aspect of small-scale interaction" (Granovetter 1973, p. 1360), specifically, the nature of network ties and their role in shaping the network as a whole. So far, we did not differentiate between types of ties. In the next section, we show that the nature of ties actually matters.

\section{TRANSACTIONS AND SOCIAL BONDS AS DETERMINANTS OF NETWORK STRUCTURES}

A fascinating aspect of polycentric structures of coordination is that their properties of clustering and connectivity, while originated from the same web of interactions, are the outcome of two conflicting tendencies. The dynamic of subgroup interaction, as it implies processes of identity construction, maintenance, and reproduction, originates from a tendency toward "particularization" and "distinction," and therefore toward closure into clusters of dense interaction. An opposite force is at work in bridging otherwise separate groups, entailing generalized patterns of interaction, hence openness. On the one hand, clustering processes imply specific, individual-oriented relations; on the other hand, connectivity and reachability imply interaction with a sort of "generalized other."

Differentiating between different types of relations might be helpful for disentangling this otherwise puzzling pattern of interaction. Earlier, we suggested that civic networks can be better understood as the composition and interplay of two different kinds of relations: transactions and social bonds. In particular, we expected social bonds to have a central role within subgroups, while transactions should operate mainly as connections among subgroups. Here, we test if the distinction between transactions and social bonds is useful to capture patterns of microinteraction and explain the emergence of structural properties of clustering and connectivity.

\footnotetext{
${ }^{16}$ Analytically, the argument could be reversed: "The quality of a dyadic relationship fundamentally changes as a function of the overall structure in which the relationship is embedded" (Krackhardt 1994, p. 21).
} 
American Journal of Sociology

Social Bonds "Within" and Transactions "Between"

In order to test whether social bonds actually characterize dense clusters within broader networks, while transactions facilitate links between almost disconnected subgroups, we first need a graph partition that is able to capture the community structure of the observed civic networks: specifically, "the division of network nodes into groups within which the network connections are dense, but between which they are sparser" (Newman and Girvan 2004, p. 1). We use Newman and Girvan's graph partitioning method, based on an iterative removal of edges for identifying cohesive areas of exchange. This enables us to differentiate several clusters and investigate relations "within" and "between" groups. Figure 3 shows the ten clusters that form the community structure of Bristol's civic network and distinguish between transactions (black lines) and social bonds (white lines). ${ }^{17}$ Table 3 reports the distribution of ties for each cluster, differentiating between transactions and social bonds. Thus, "within" columns indicate how many ties connect nodes located in the same cluster, while "between" columns report ties from nodes in one cluster to nodes in other clusters. ${ }^{18}$

We expect the web within clusters to be characterized by (and to develop through) social bonds; on the contrary, we see the connection among clusters as more likely to arise through transactions. Consequently, we expect a different ratio of social bonds and transactions in within and between clusters. In general, in Bristol there are 1.3 social bonds for each transaction. If we consider only relations within clusters, this ratio grows to 1.7 and decreases to .5 for the links between groups. Therefore, in the exchange between organizations in different clusters, we have two transactions for each social bond.

In order to account for differences among clusters in the general distribution of social bonds and transactions, each within (or between) ratio of cluster $x$ has been standardized by dividing it by the overall ratio of cluster $x$.

$$
\text { index }_{\text {in }}=\frac{\text { socbonds }_{\text {inx }_{x}} / \text { trans }_{i n_{x}}}{\text { socbonds }_{\text {all }_{x}} \text { trans }_{\text {all }_{x}}}
$$

\footnotetext{
${ }^{17}$ We requested 12 clusters, a number that was reduced to 10 because in two clusters there were only one and two nodes (not enough to speak about groups, interaction, etc.). These three nodes have been placed in the cluster with which they have the highest number of links.

${ }^{18}$ We refer to the number of nodes rather than to the number of links because this facilitates the comparison between in and out. If we referred to the number of links, it would be difficult to account for the number of links between clusters. Anyway, the number within each group can be easily computed as the number of nodes/2.
} 


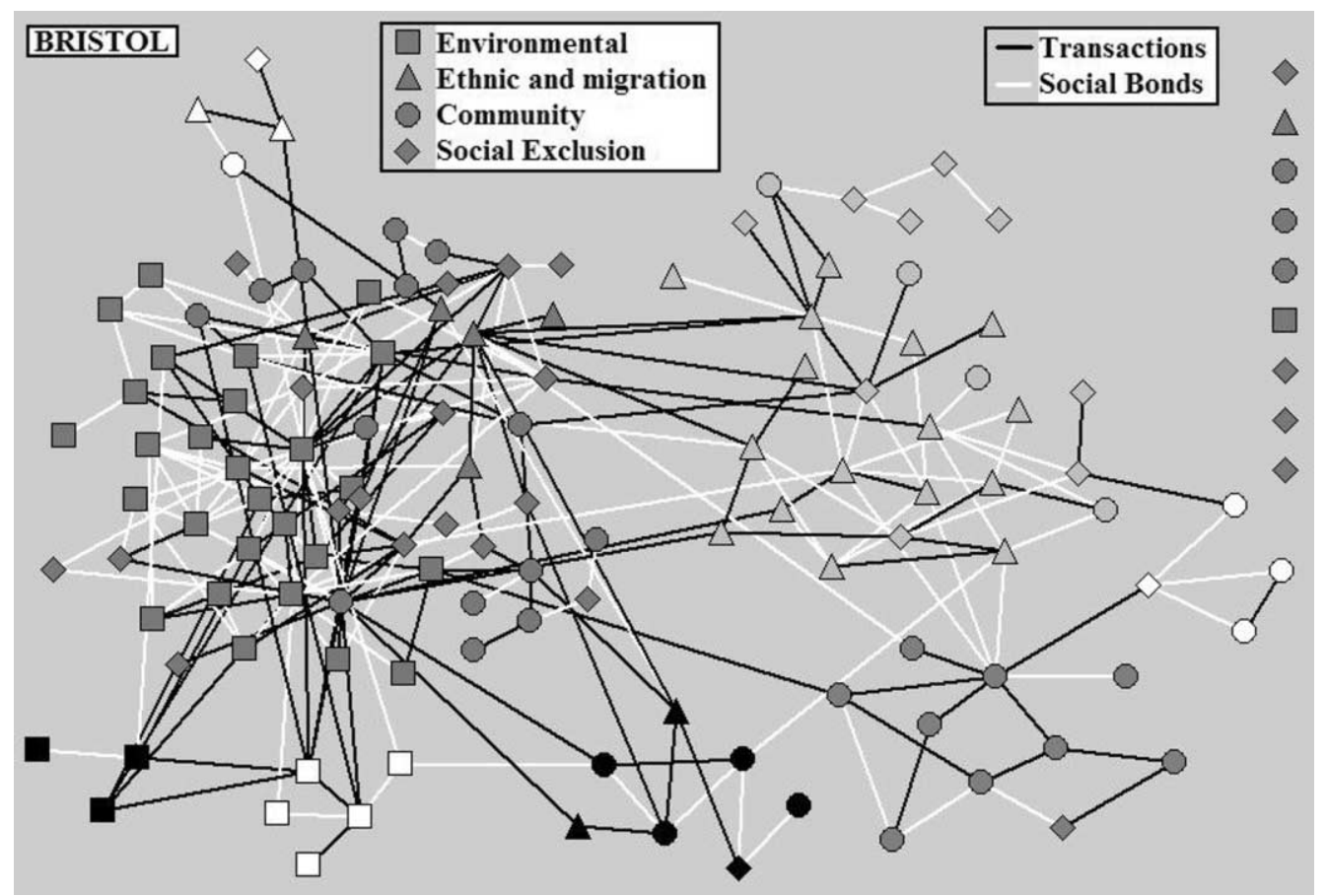

FIG. 3.-Community structure in Bristol. The graph shows the clusters obtained using the Newman-Girvan partitioning algorithm. Isolated organizations are listed vertically in the bottom right corner of the table. The shape of the nodes indicates the type of organization: environmental (square), ethnic minorities and migrants (triangle), community (circle), and social exclusion and human rights (diamond). Black ties are transactions, and white ties are social bonds. 
TABLE 3

Distribution of Transactions and Social Bonds within and between Clusters in Bristol

\begin{tabular}{|c|c|c|c|c|c|c|c|c|c|c|c|c|}
\hline \multirow[b]{2}{*}{ Clusters } & \multirow[b]{2}{*}{$\begin{array}{l}\text { No. of } \\
\text { Nodes }\end{array}$} & \multicolumn{3}{|c|}{ SOCIAL BONDS } & \multicolumn{3}{|c|}{ TRANSACTIONS } & \multicolumn{3}{|c|}{$\begin{array}{l}\text { Social Bonds/ } \\
\text { Transactions }\end{array}$} & \multicolumn{2}{|c|}{ INDEX } \\
\hline & & Within & Between & All & Within & Between & All & Within & Between & All & Within & Between \\
\hline$\ldots \ldots \ldots$ & Nine isolates & & & & & & & & & & & \\
\hline $2 \ldots \ldots \ldots \ldots$ & 4 & 6 & 1 & 7 & 2 & 1 & 3 & 3.0 & 1.0 & 2.3 & 1.3 & .4 \\
\hline $3 \ldots \ldots \ldots \ldots$ & 51 & 136 & 10 & 146 & 70 & 24 & 94 & 1.9 & .4 & 1.6 & 1.3 & .3 \\
\hline $4 \ldots \ldots \ldots \ldots$ & 10 & 8 & 4 & 12 & 18 & 2 & 20 & .4 & 2.0 & .6 & .7 & 3.3 \\
\hline $5, \ldots \ldots \ldots \ldots$ & 29 & 52 & 7 & 59 & 30 & 8 & 38 & 1.7 & .9 & 1.6 & 1.1 & .6 \\
\hline $6 \ldots \ldots \ldots \ldots$ & 3 & 4 & 3 & 7 & 0 & 4 & 4 & $(\infty)$ & .8 & 1.8 & $(\infty)$ & .4 \\
\hline $7 \ldots \ldots \ldots \ldots$ & 5 & 4 & 4 & 8 & 4 & 7 & 11 & 1.0 & .6 & .7 & 1.4 & .8 \\
\hline $8 \ldots \ldots \ldots \ldots$ & 8 & 12 & 1 & 13 & 6 & 8 & 14 & 2.0 & .1 & .9 & 2.2 & .1 \\
\hline $9 \ldots \ldots \ldots \ldots$ & 4 & 4 & 1 & 5 & 2 & 2 & 4 & 2.0 & .5 & 1.3 & 1.6 & .4 \\
\hline $10 \ldots \ldots \ldots \ldots$ & 11 & 20 & 1 & 21 & 12 & 10 & 22 & 1.7 & .1 & 1.0 & 1.7 & .1 \\
\hline Total .......... & & 245 & 33 & 278 & 145 & 65 & 210 & 1.7 & .5 & 1.3 & 1.3 & .4 \\
\hline
\end{tabular}

NotE. - Number of within and between links by clusters and relative indexes. Newman and Girvan's graph partitioning method. 


\section{Civic Networks}

This index can be interpreted as follows: the chance to observe a social bond rather than a transaction within the cluster $x$ is number of index times higher than expected according to the overall distribution of social bonds and transactions of cluster $x$. For instance, in the within relations of cluster 2, a social bond is 1.3 times more likely to be present than expected according to the overall distribution of transactions and social bonds in cluster 2 .

In sum, both the general ratio (social bonds/transactions) and the ratios of each cluster show that, all the rest being equal, organizations in the same cluster are more likely to exchange through social bonds (in fact, all values are higher than one, except for cluster 4), while organizations from different clusters have a higher chance to be linked through transactions. We obtained similar results also for Glasgow, where six clusters were identified (fig. 4 ; table 4). ${ }^{19}$

So far we observed that different types of relations take place among organizations and that they are differently distributed across different clusters in the network. To demonstrate that the peculiar distribution of transactions and social bonds is actually responsible for shaping civic network structures, we now randomly rewire either transactions or social bonds and consider changes in relevant structural measures with respect to the observed civic networks. ${ }^{20}$ This procedure enables us to infer to what extent observed structural properties are due to the peculiar configuration of links or are simply determined by chance (Bearman et al. 2004).

In general, given the polycentric structure of civic networks, a random rewiring of links should reduce clustering and increase the level of hierarchy. This is due to the fact that introducing random patterns of interaction weakens the network tendency toward forms of balanced interdependence. Since we argue that social bonds are mainly responsible for such clustering tendency, we expect the random rewiring of social bonds to have a stronger impact on hierarchy and clustering than the random rewiring of transactions.

Similarly, a random rewiring of links should increase network connectivity (specifically, it should induce higher connectedness and shorter path length), since random networks minimize redundant links, thus maximizing reachability. According to our theory, transactions are supposed to be mainly responsible for levels of network connectivity. Given that

\footnotetext{
${ }^{19}$ We obtained eight clusters, then reduced to six because two clusters were composed by less than three nodes. Remaining nodes have been assigned to the clusters to which they were connected.

${ }^{20}$ Specifically, we select edges at random and rewire the end point to a randomly chosen node.
} 


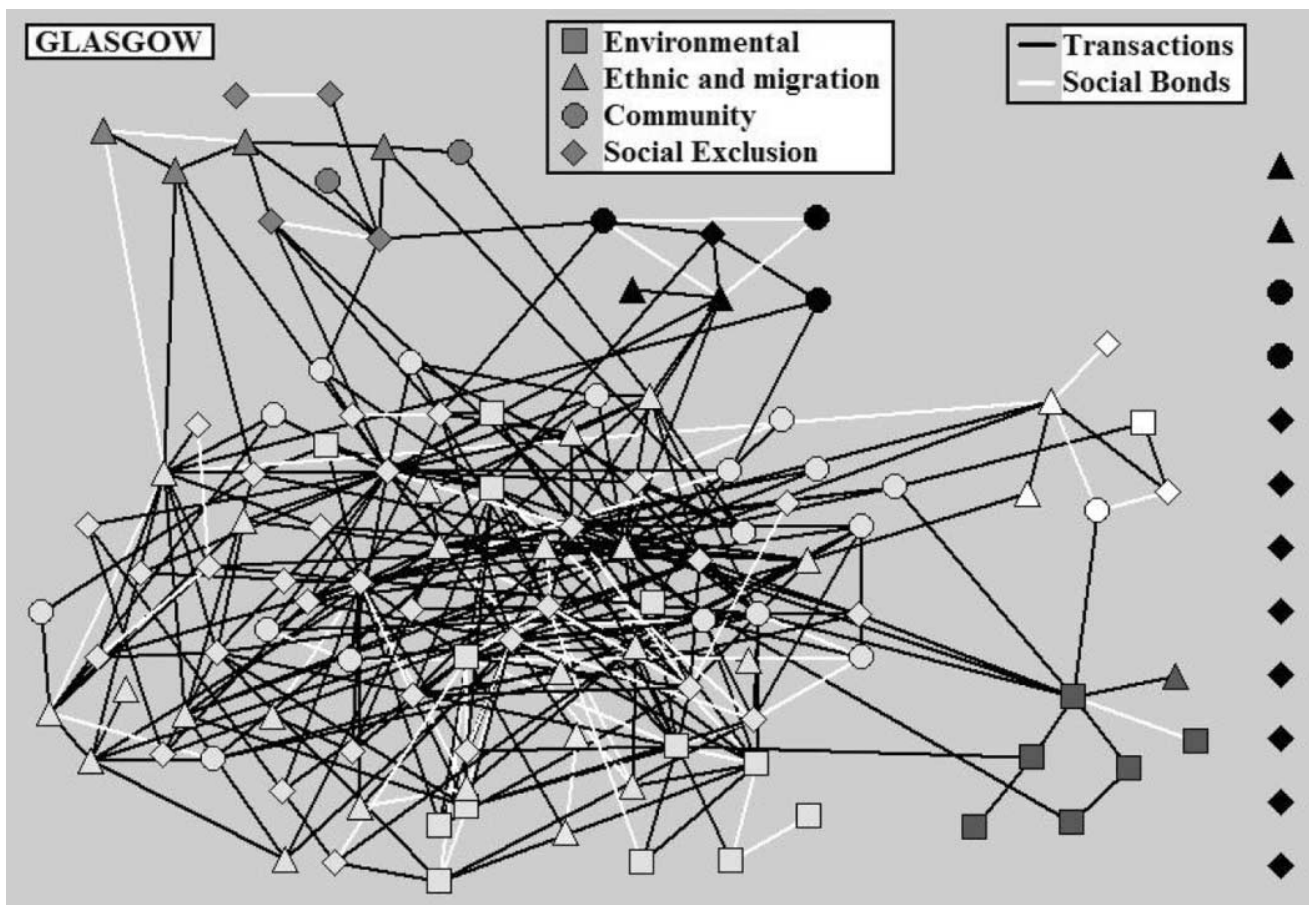

FIG. 4.-Community structure in Glasgow. The graph shows the clusters obtained using the Newman-Girvan partitioning algorithm. Isolated organizations are listed vertically in the bottom right corner of the table. The shape of the nodes indicates the type of organization: environmental (square), ethnic minorities and migrants (triangle), community (circle), and social exclusion and human rights (diamond). Black ties are transactions, and white ties are social bonds. 
TABLE 4

Distribution of Transactions and Social Bonds within and between Clusters in Glasgow

\begin{tabular}{|c|c|c|c|c|c|c|c|c|c|c|c|c|}
\hline \multirow[b]{2}{*}{ Cluusters } & \multirow{2}{*}{$\begin{array}{l}\text { No. OF } \\
\text { Nodes }\end{array}$} & \multicolumn{3}{|c|}{ Social Bonds } & \multicolumn{3}{|c|}{ Transactions } & \multicolumn{3}{|c|}{$\begin{array}{l}\text { SocIal Bonds/ } \\
\text { TranSACTIONS }\end{array}$} & \multicolumn{2}{|c|}{ INDEX } \\
\hline & & Within & Between & All & Within & Between & All & Within & Between & All & Within & Between \\
\hline $1 \ldots \ldots \ldots \ldots$ & 12 isolates & & & & & & & & & & & \\
\hline $2 \ldots \ldots \ldots \ldots$ & 10 & 6 & 1 & 7 & 18 & 8 & 26 & .3 & .1 & .3 & 1.24 & .46 \\
\hline $3 \ldots \ldots \ldots \ldots$ & 6 & 6 & 1 & 7 & 6 & 5 & 11 & 1.0 & .2 & .6 & 1.57 & .31 \\
\hline Total .......... & 124 & 144 & 4 & 148 & 437 & 59 & 496 & .3 & .1 & .3 & 1.104 & .227 \\
\hline
\end{tabular}

NotE. - Number of within and between links by clusters and relative indexes. Newman and Girvan's graph partitioning method. 
American Journal of Sociology

network connectivity in polycentric networks is usually due to few random links that span across dense clusters of interaction, we expect the effect of transactions to resemble that of those random ties. In the extreme case, one in which transactions are not affected by any selectivity in the choice of partners, the effect of their rewiring on connectivity measures should be null. In reality, the impact of transaction rewiring on connectivity measures is expected to be lower than that of social bonds, as the former ties are less affected by selectivity criteria and thus more likely to connect otherwise disconnected groups.

We ran 1,000 simulations rewiring either transactions or social bonds and computed the mean values for the four graph-level indexes previously introduced-hierarchy, connectedness, average path length, and clustering. In figure 5 we contrast these values with the box-plot distributions presented in figure 2. The squares indicate the mean value for the rewiring of transactions, while the triangles refer to the rewiring of social bonds. The dark dots report, as before, the value for the observed networks.

The tests produce once again similar results in both cities and confirm that the nature of links matters. This is particularly evident for measures of hierarchy and clustering. The random rewiring of social bonds reduces the level of clustering observed in the network by a much higher amount than the rewiring of transactions. Social bonds are also strongly responsible for the low level of hierarchy observed in the network. In fact, when these ties are rewired, the measure of hierarchy strongly increases. On the contrary, transactions do not seem to have a great impact in determining the tendency toward decentralized, nonhierarchical patterns of alliances.

As for measures of connectedness and average path length, the random rewiring of transactions and social bonds has partially different effects in the two cities, because differences induced by random rewiring depend on the original characteristics of the graph. Consistent with the fact that random networks have higher levels of connectivity, random rewiring reduces the average path length and increases the level of connectedness, with two exceptions: random rewiring does not increase any further the level of connectedness in Bristol because the original value is already close to the maximum, and it does not reduce by a great amount the average path length in Glasgow because such a measure there is already minimal. In general, results only partially support the hypothesis that transactions are deployed at random. In fact, random rewiring of transactions is less conducive to change than social bonds only (and by very small numbers) with respect to the measure of average path length. In light of this and previous analyses, we conclude that transactions foster high levels of connectivity, even though their distribution is not completely random. 

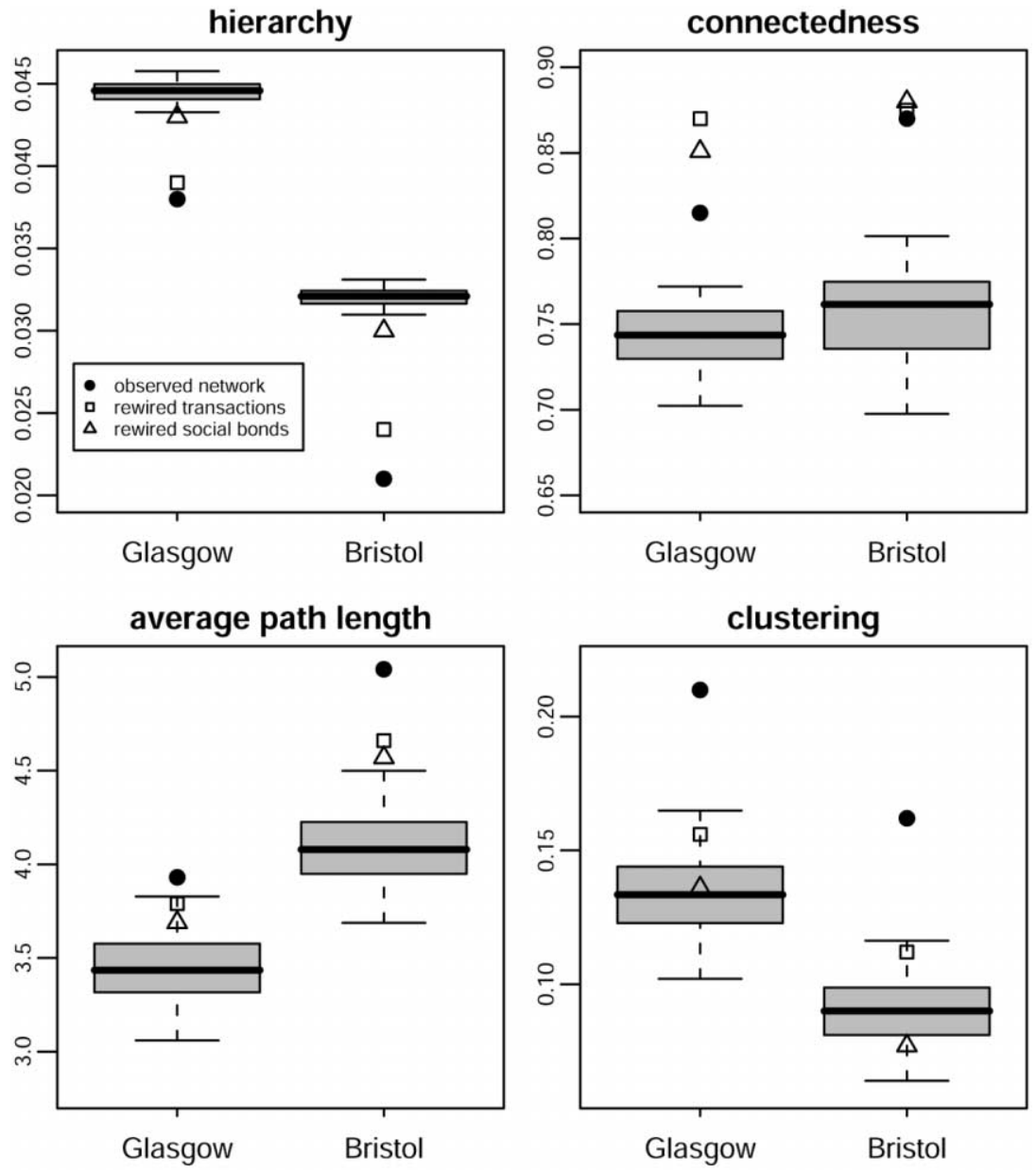

FIG. 5.-Graph measures and random rewiring of transactions and social bonds. For each of the four structural measures of interest (hierarchy, connectedness, average path length, and clustering), the plot compares values for observed networks (dots), random rewiring of transactions (squares), and random rewiring of social bonds (triangles) to the distribution of values obtained from 1,000 simulated random graphs with preserved degree distribution (box plots). Whiskers extend to the most extreme datapoint that is no more than 1.5 times the interquartile range from the box. Glasgow and Bristol. 


\section{American Journal of Sociology}

More likely, transactions are deployed according to "quasi-random" criteria, with weak constraints on partner selectivity.

In sum, the peculiar interplay of social bonds and transactions at the level of small-scale interactions is responsible for the simultaneity of clustering and connectivity in civic networks, with social bonds largely accounting for clustering and decentralization, and transactions contributing to the overall integration of the networks. Altogether, this finding underlines the role of different kinds of links in the production of micro- and macrointegration. Specifically, we demonstrate that social bonds characterize collaborative patterns within niches of intense interaction, an exclusive, inward-looking form of collaboration likely to strengthen interorganizational bonds, while transactions disproportionately differentiate those collaborative ties that span across otherwise disconnected clusters of organizations and therefore foster civil society macrointegration.

\section{Solidarity, Recognition, and In-group Selection}

In our framework, social bonds and transactions serve different goals: one is about identity building, reinforcement, and construction of solidarity, the other about the setting up of alliances that are not binding in the longer term (or at least need not be) in order to achieve short-term results. Here we show that organizations deploy transactions and social bonds consistently: first, we test the hypothesis that organizations that are connected through social bonds are also likely to be bounded by feelings of solidarity and mutual recognition; second, that organizations are involved in deeper, longer-term relations with actors mobilized on their same issues, while at the same time being open to building ad hoc, short-term alliances with a broader range of civic organizations not so closely involved with their main agenda. While the former ties strengthen the sense of commitment and solidarity, the latter exploit contacts with a broader environment, maximizing the spot mobilized around specific issues.

According to the first hypothesis, social bonds are more likely to involve symmetric ties and solidarity. We therefore regress distinct matrices reporting symmetric ties and feelings of solidarity on transactions and social bonds (table 5). ${ }^{21}$ As expected, social bonds are more powerful predictors of the presence of symmetric ties and feelings of solidarity between organizations, which confirms our understanding of social bonds as orga-

\footnotetext{
${ }^{21}$ When respondents identified another organization as a major partner, they were also asked if they felt broad solidarity feelings toward that organization. That need not necessarily be the case, as alliances may be driven by purely instrumental motives.
} 
Civic Networks

TABLE 5

Regressions of Reciprocity/Solidarity on Transactions and Social BondS

\begin{tabular}{|c|c|c|c|c|}
\hline & \multicolumn{2}{|l|}{ MODEL 1} & \multicolumn{2}{|l|}{ MODEL 2} \\
\hline & Symmetric Ties (SCs) & $\overline{R^{2}}$ & Solidarity Ties (SCs) & $R^{2}$ \\
\hline \multicolumn{5}{|l|}{ Glasgow: } \\
\hline Transactions ...... & .340 & .306 & .213 & .466 \\
\hline Social bonds ...... & .439 & & .651 & \\
\hline \multicolumn{5}{|l|}{ Bristol: } \\
\hline Transactions ....... & 248 & .277 & .190 & .525 \\
\hline Social bonds ....... & .470 & & .703 & \\
\hline
\end{tabular}

NoTE.-Distinct matrices of symmetric and solidarity ties were regressed on transactions and social bonds (QAP, 2,000 permutations). The table reports coefficients and model fit of two models for each city: the matrix of symmetric ties is the dependent variable in model 1 , while the matrix of solidarity ties is the dependent variable in model 2. Glasgow and Bristol. SC $=$ standard coefficients.

nizational relationships that go beyond the limits of the specific actions on which organizations happen to collaborate.

In order to test the second hypothesis, we used the same index previously computed for comparing the distribution of ties within and between clusters, but this time, instead of looking at clusters, we considered the distribution of ties between sets of organizations, which differed according to their main issue-environment, ethnic minorities, community, and social exclusion. Tables 6 and 7 report the results for this test. Social bonds prevail in shaping relations among organizations pursuing the same substantive interests; in contrast, transactions characterize exchanges between organizations whose primary, broad agendas are different.

In sum, from the analysis, we observe that transactions and social bonds distribute differently not only within and across areas of dense interaction, but also within and across sets of organizations defined by specific issue interests. One can reasonably ask whether clusters partition and issue classification closely resemble each other or not. In principle, clusters of dense interaction might consist of organizations focusing on the same issue. Empirically, this is not the case. As figures 2 and 3 clearly show, clusters of dense interaction usually include organizations with different issue priorities. Exceptions are three small clusters, consisting respectively of two, three, and five organizations all focusing on environmental issues. Apart from that, however, organizations focusing on at least two different issues may be found in each cluster. In some clusters, some issues prevail; in others there is a complete balance between them.

That there is no general overlap between density of interaction and organizations' main issues makes the strategic deployment of transactions and social bonds even more interesting. Organizations seem to follow a twofold pattern of interaction, developing stronger relations with civic 
TABLE 6

Distribution of Transactions and Social Bonds within and Between Issue Types in Bristol

\begin{tabular}{|c|c|c|c|c|c|c|c|c|c|c|c|c|}
\hline \multirow[b]{2}{*}{ Issue } & \multirow[b]{2}{*}{ No. } & \multicolumn{3}{|c|}{ SOCIAL BONDS } & \multicolumn{3}{|c|}{ Transactions } & \multicolumn{3}{|c|}{$\begin{array}{l}\text { Social Bonds/ } \\
\text { TRANSACTIONS }\end{array}$} & \multicolumn{2}{|c|}{ INDEX } \\
\hline & & Within & Between & All & Wthin & Between & All & Within & Between & All & Within & Between \\
\hline Environment $\ldots \ldots \ldots \ldots$ & 36 & 84 & 31 & 115 & 50 & 27 & 77 & 1.68 & 1.15 & 1.49 & 1.12 & 1.02 \\
\hline Ethnic minorities ....... & 26 & 32 & 22 & 54 & 26 & 34 & 60 & 1.23 & .65 & .90 & 1.37 & .47 \\
\hline Community & 34 & 20 & 26 & 46 & 32 & 38 & 70 & 63 & 68 & 66 & .95 & .72 \\
\hline Social exclusion .......... & 38 & 20 & 43 & 63 & 2 & 43 & 45 & 10.00 & 1.00 & 1.40 & 7.14 & .14 \\
\hline
\end{tabular}

TABLE 7

Distribution of Transactions and Social Bonds within and Between Issue Types in Glasgow

\begin{tabular}{|c|c|c|c|c|c|c|c|c|c|c|c|c|}
\hline \multirow[b]{2}{*}{ Issue } & \multirow[b]{2}{*}{ No. } & \multicolumn{3}{|c|}{ SOCIAL Bonds } & \multicolumn{3}{|c|}{ TRAnsactions } & \multicolumn{3}{|c|}{$\begin{array}{l}\text { Social Bonds/ } \\
\text { TRANSACTIONS }\end{array}$} & \multicolumn{2}{|c|}{ INDEX } \\
\hline & & Within & Between & All & Within & Between & All & Within & Between & All & Within & Between \\
\hline Environment . & 20 & 20 & 7 & 27 & 36 & 56 & 92 & .56 & .13 & .29 & 1.89 & .07 \\
\hline Ethnic minorities ....... & 35 & 18 & 11 & 29 & 76 & 84 & 160 & .24 & .13 & 18 & 1.31 & .10 \\
\hline Community & 28 & 12 & 8 & 20 & 24 & 65 & 89 & .50 & .12 & .22 & 2.23 & .06 \\
\hline Social exclusion $\ldots \ldots \ldots$ & 41 & 24 & 18 & 42 & 76 & 128 & 204 & .32 & .14 & .21 & 1.53 & .09 \\
\hline
\end{tabular}


Civic Networks

organizations that have their same interests, and instrumental, ad hoc alliances with organizations that are only marginally committed to their main goal. In doing so, they generate a web of interactions that is dense enough to provide them with mutual support, but at the same time open enough to maintain a certain level of overall connectivity and issue heterogeneity.

\section{CONCLUSION}

This article contributes to the analysis of political networks by paying simultaneous attention to both the formal properties and the content of network ties. This approach identifies structural patterns that are remarkably similar in as diverse locations as Glasgow and Bristol. In both cities:

1. A polycentric, horizontally integrated structure prevails over a hierarchical, centralized one. Civic networks are found to consist of internally dense clusters, connected to each other by a smaller number of bridging ties.

2. The content of ties shapes the overall network structure in significant ways: strong identity ties ("social bonds") embed associations into dense clusters of interaction, while more instrumental, ad hoc alliances ("transactions") operate across clusters, integrating them into broader civic networks.

This particular distribution of instrumental, "weak" transactions and identity-based, "strong" social bonds actually provides the basis for both micro- and macrointegration within civil society: in fact, it generates networks tight enough to embed civic associations in a distinctive environment, but open enough to connect them to a broader and more heterogeneous range of civic organizations. In both localities, stronger social bonds are more likely to be found between associations sharing the same broad agenda, while more instrumental transactions tend to prevail between associations with different agendas.

What we found on the formal properties of civic networks is consistent with earlier insights from both social movements and community studies. First, the model of polycentric coordination that emerges from our study of civic networks closely resembles Gerlach's (Gerlach and Hine 1970; Gerlach 2001) classic view of social movements as segmentary, polycentric, and integrated structures of political action. In his seminal explorations, Gerlach drew mostly on countercultural or subcultural movements, such as the Black Power or revivalist Christian movements, and pointed at the positive consequences deriving for those movements from such network structures (e.g., their increased capacity to withstand repression). In 
American Journal of Sociology

a functional vein, he concluded that a structure based on dense clusters connected by sparse bridging relations best served collective actors' need to reduce the costs of repression. In contrast, here we looked at far more heterogeneous organizations. Most of them do not perceive themselves as "social movement organizations" or display some of the latter's most distinctive features, nor do they feel exposed to high risks of repression. If the same network structure may be found in organizational populations that are so diverse in their level of political or cultural radicalism, then such structural configuration might be characteristic of much broader and differentiated populations of political actors and reflect more generally applicable organizational logics.

The model of civic coordination we observed also supports the pluralistic view of power structures, according to which local politics is dominated by a shifting plurality of major political actors rather than a cohesive, densely connected elite (Dahl 1961; Knoke 1990). As Laumann and Pappi (1973, p. 227) showed, "the fault lines of the oppositional structures and the personnel active on each of the issues do change from one functional issue to another." However, while earlier work on local political networks focused mainly on elite structures (no matter how internally differentiated), we reach similar conclusions from the perspective of grassroots participation. That sustained patterns of collaboration among civil society organizations cut across interest lines, thus creating the preconditions for shifting alliances and simultaneously contributing to the overall integration of civil society, is one more illustration of the paradoxical idea that "crosscutting lines of differentiation foster processes of social integration, and they also foster processes of recurrent change" (Blau 1974, p. 615).

Taken together, our main findings both support and enrich recent calls for the development of broad analytical schemes for the analysis of civic and political action, encompassing both protest and institutional politics, as well as elite-driven and populist attempts to shape the political process (e.g., McAdam, Tarrow, and Tilly 2001; Sampson et al. 2005). Our structural approach to civil society also raises important questions for two related yet distinctive lines of research: one, focusing on the relationship between social capital and social integration; the other, on the role of political contexts (or "opportunity structures") as determinants of the intensity and form of collective action.

With their clustering and connectivity properties, polycentric forms of civic coordination can enhance the social capital of civic organizations. In fact, according to a structural approach to social capital, closure and brokerage are the complementary properties that "together define social capital," here understood as a way of facilitating coordinated action and creating "for individuals and groups an advantage in pursuing their ends" 


\section{Civic Networks}

(Burt 2005, p. 7). In general terms, while brokerage improves vision through the circulation of information and new ideas and mediates between alternative positions, network closure results, among other things, in the strengthening of social relations and the enforcement of group norms.

Closure and brokerage are complementary to each other in the production of social capital. In our study, we show this to occur when associations, in their ordinary activity, engage in multiplex relational patterns, balancing between transactions and social bonds. Substantive deviations from this model might undermine social integration and eventually lead toward different forms of social fragmentation. If social bonds were dominant, their propensity to generate triadic patterns of interaction would lead to the fragmentation of civic networks into disconnected, internally cohesive clusters (fig. 6, left). Group identities would become exclusive, and civil society would split into conflicting, noncommunicating camps. If, in contrast, civic networks were only based on ad hoc alliances and instrumental transactions, then civil society would most likely consist of quasi-random, contingent patterns of relations. These would hardly be conducive to the emergence of the longer-term solidarities and deeper social bonds usually associated with social integration (fig. 6, right).

The implications of the second scenario - the one assuming a total prevalence of instrumental transactions - have repeatedly been highlighted by analysts of civil society on both sides of the Atlantic. The decline in individual involvement in associations and the progressive professionalism of the civic sector might indeed undermine civic associations' capacity to develop and maintain social bonds based on personal ties. A substantive reduction of identity relationships might lead to an undifferentiated associational model in which associations interact on the basis of ad hoc, instrumental relations that do not promote broader identities and horizontal solidarity.

For example, in the United Kingdom, many have denounced the risks attached to the growing professionalism and reduction in the active citizenry, the most prominent being the diminished capacity of civil society to develop horizontal, grassroots forms of cooperation and the crisis of social capital in civil society (Knight and Stokes 1996; Lowndes et al. 2001; Taylor 2003). Along similar lines, many have documented the increasing level of professionalism and specialization of voluntary associations in the United States, at the same time voicing the fear that associational differentiation may result in the deepening of social and economic divisions in American society (Wuthnow 1998; Skocpol 2003). Previous research has conclusively shown how important alliance building is as a tool to overcome the shortage of resources and influence experienced by many civic organizations-especially those acting on behalf of the most 

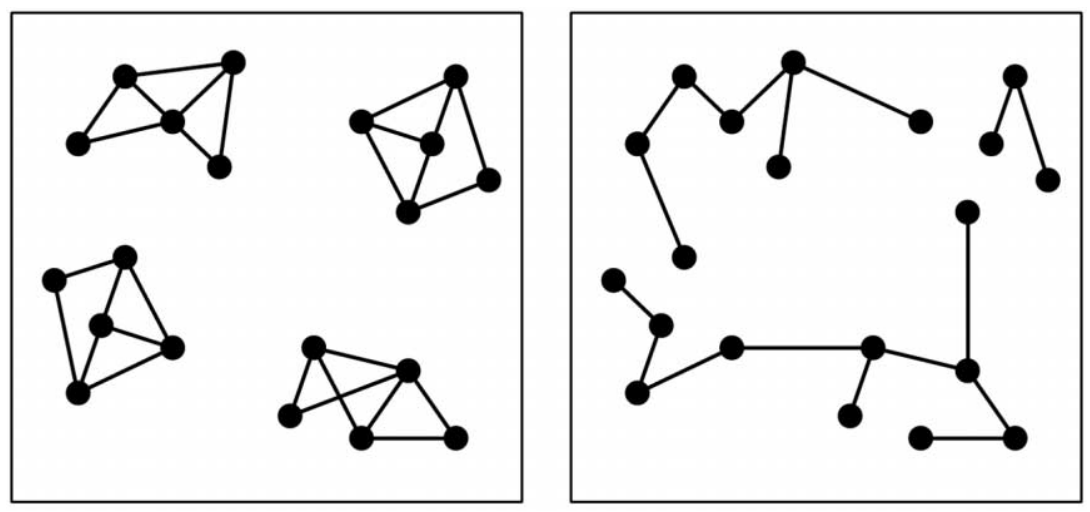

FIG. 6.-Extreme cases in a polycentric model of coordination

deprived constituencies (Knoke 1990). If rates of associational involvement-and in particular, obviously, of multiple memberships-were to fall dramatically, then the opportunities for alliance building created by this type of connections would drop accordingly. The greater coordination efforts required by the building of ad hoc coalitions on each single issue would be most easily sustainable by the best-endowed organizations, and this would end up deepening inequalities of access to the polity.

Let us now look at the other extreme scenario, entailing the prevalence of social bonds within civic networks-and hence the rise in rates of associational involvement and multiple memberships. Here, the implications of this trend are perhaps less obvious. Scholars usually assume that high levels of individual participation and associational density are good for democracy and conversely see the decline of individual memberships as a threat to social integration (for a review of the debate, see Fung [2003]). However, this need not be necessarily the case.

According to our analysis, the interorganizational links created by multiple memberships tend, consistent with balance theory, to cluster within tightly connected groups. Civic networks with a large proportion of social bonds are therefore at risk of social fragmentation and factionalism, an aspect that casts doubts on the generally optimistic view of individual participation in associations. The consequence of an increasing involvement of citizens in associations might not necessarily be the overall integration of society but its deeper fragmentation in distinct, noncommunicating clusters. This point has obviously been made many times before, whether in reference to the demise of democracy in Weimar Germany (Allen 1984) or to the various instances (mafia families, Northern 
Ireland religious communities, or the KKK) in which "bonding social capital" is clearly detrimental to civic integration.

What our analysis-somehow worryingly — suggests is that the negative effects of dense associational memberships might not be restricted to the usual suspects: indeed, it is the growth beyond a certain level that threatens the integration of civil society, regardless of whether the activities that generate it be intrinsically "good" or "bad" for democracy. The integration of civil society seems rather to rest on the precarious balance of the two different logics of action we have identified. This runs counter to overly optimistic views of participatory, populist democracy, particularly popular among social movement analysts (Baiocchi 2001; Medearis 2005; della Porta and Diani 2006, pp. 239-45). It might also prompt a critical reassessment of theories of democracy emphasizing the risk of "political overloading" for contemporary democracies (Crozier, Huntington, and Watanuki 1975; Hagopian 2000).

An area in which our analysis does not reach firm conclusions yet poses provoking questions concerns the relationship between the network forms of collective action and their political and institutional setting. Over the last decades, the political process approach has placed contextual and institutional variables at the core of scholarly accounts of the intensity and forms of political participation at both the individual and the group level (for a recent summary, see Kriesi [2004]). However, the relationship between political opportunities and the structure of interorganizational networks has received only scant attention (among the few exceptions are Rucht [1989], Diani [2003], Osa [2003]). Here, we expected political opportunities to affect crucial network features in at least two ways. On the one hand, we thought that the increasing professionalization of the voluntary and community sector and its growing involvement in policy making at the local level, both UK-wide trends encouraged by New Labour policies (Daly 2006), would have led to hierarchical, centralized networks in both cities. As civic organizations depended less on broad-based, grassroots campaigning and felt encouraged to secure their own niche through higher division of labor, this might have resulted in their working largely on their own while developing a few instrumental ties to a small number of central, highly influential actors within the sector. As it were, both Bristol and Glasgow turned out to display nonhierarchical, polycentric structures.

On the other hand, we expected the deep differences between the two cities regarding the salience of traditional political cleavages, most notably the class one, to reflect in network structures too. When ideological differences are strong, fragmentation of civil society into distinct, noncommunicating, internally dense clusters is in order (Linz 1967; Sawer and Grove 1994). In contrast, when the salience of existing cleavages is low, 


\section{American Journal of Sociology}

centralized structures, connected through a small number of core organizations, seem more likely (Lowe and Goyder 1983; Diani 2003). In our specific cases, the lesser salience of classic social and political cleavages in Bristol would lead us to expect civic networks to be more centralized and more hierarchical there than in Glasgow: once again, though, our expectations were confounded, as the two cities showed remarkably similar structures.

Despite the substantive differences between Glasgow and Bristol in both their socioeconomic profile and their political tradition, civic networks actually display the same structural properties in both cities, suggesting that fundamental relational mechanisms are consistent across different social and political contexts. Of course, this might be due to the fact that Bristol and Glasgow are actually more similar than one would stipulate if one adopted a too close, local perspective. For all their differences, they are both located in the same democratic system, involved in the same national political, cultural, and media arenas.

And yet, while we are far from considering the polycentric model of coordination a universal feature of civic networks, we nonetheless think that the scope conditions of our findings go beyond the two cities here investigated. Our analysis is not limited to the description of similar network structures, but shows that in both cities the same microrelational mechanisms and organizational logics are at work in bringing about certain macroproperties. This suggests that organizational patterns of interaction might be largely independent of local conditions and mostly driven by the intrinsic properties of the relations in which actors are embedded. At least this is what we observed. It may not be the case everywhere, and comparisons of civic networks in different democratic systems, or also including semiauthoritarian regimes, might yield different results. But it is definitely a finding worth further investigation.

\section{REFERENCES}

Allen, William S. 1984. The Nazi Seizure of Power: The Experience of a Single German Town, 1922-1945. New York: Franklin Watts.

Anderson, Brigham S., Carter Butts, and Kathleen Carley. 1999. "The Interaction of Size and Density with Graph-Level Indices.” Social Networks 21:239-67.

Ansell, Christopher K. 2003. "Community Embeddedness and Collaborative Governance in the San Francisco Bay Area Environmental Movement." Pp. 123-44 in Social Movements and Networks, edited by Mario Diani and Doug McAdam. Oxford: Oxford University Press.

Baiocchi, Gianpaolo. 2001. "Participation, Activism, and Politics: The Porto Alegre Experiment and Deliberative Democratic Theory." Politics and Society 29:43-72.

Bearman, Peter, James Moody, and Katherine Stovel. 2004. "Chains of Affection: The Structure of Adolescent Romantic and Sexual Networks." American Journal of Sociology 110:44-91. 


\section{Civic Networks}

Blau, Peter M. 1974. "Parameters of Social Structure." American Sociological Review 39:615-35.

Borgatti, Stephen P., Martin G. Everett, and Linton C. Freeman. 2002. Ucinet for Windows: Software for Social Network Analysis. Cambridge, Mass.: Analytic Technologies.

Borgatti, Stephen P., and Pacey C. Foster. 2003. "The Network Paradigm in Organizational Research: A Review and Typology." Journal of Management 29: 991-1013.

Breiger, Ronald, and Philippa Pattison 1978. "The Joint Role Structure of Two Communities' Elites." Sociological Methods and Research 7 (2): 213-26.

Burt, Ronald S. 2005. Brokerage and Closure: An Introduction to Social Capital. New York: Oxford University Press.

Carroll, William K., and R. S. Ratner. 1996. "Master Framing and Cross-Movement Networking in Contemporary Social Movements." Sociological Quarterly 37:601-25.

Cartwright, Dorwin, and Frank Harary. 1956. "Structural Balance: A Generalization of Heider's Theory." Psychological Review 63:277-93.

Cohen, Jean, and Andrew Arato. 1992. Civil Society and Political Theory. Cambridge, Mass.: MIT Press.

Cornwell, Benjamin, and Jill Ann Harrison. 2004. "Union Members and Voluntary Associations." American Sociological Review 69:862-81.

Crozier, Michel, Samuel Huntington, and Joji Watanuki. 1975. The Crisis of Democracy. New York: New York University Press.

Dahl, Robert A. 1961. Who Governs? Democracy and Power in an American City. New Haven, Conn.: Yale University Press.

Daly, Siobhan. 2006. For the Common Good? The Changing Role of Civil Society in the UK and Ireland. London: Carnegie UK Trust.

della Porta, Donatella, and Mario Diani. 2006. Social Movements, 2d ed. Malden, Mass.: Blackwell.

Diamond, Larry. 1994. "Rethinking Civil Society: Toward Democratic Consolidation." Journal of Democracy 5:4-17

Diani, Mario. 1995. Green Networks: A Structural Analysis of the Italian Environmental Movement. Edinburgh: Edinburgh University Press.

. 2003. "Leaders or Brokers?" Pp. 105-22 in Social Movements and Networks, edited by Mario Diani and Doug McAdam. Oxford: Oxford University Press.

Edwards, Bob, Michael W. Foley, and Mario Diani, eds. 2001. Beyond Tocqueville: Social Capital, Civil Society, and Political Process in Comparative Perspective. Hanover, N.H.: University Press of New England.

Friedkin, Noah. 1980. "A Test of the Structural Features of Granovetter's 'Strength of Weak Ties' Theory." Social Networks 2:411-22.

Fung, Archon. 2003. "Associations and Democracy: Between Theories, Hopes, and Realities." Annual Review of Sociology 29:515-39.

Galaskiewicz, Joseph. 1989. "Interorganizational Networks Mobilizing Action at the Metropolitan Level." Pp. 81-96 in Networks of Power, edited by Robert Perrucci and Harry Porter. New York: Aldine de Gruyer.

Gamson, William. 1975. The Strategy of Social Protest. Homewood, Ill.: Dorsey.

Gerlach, Luther. 2001. "The Structure of Social Movements: Environmental Activism and Its Opponents." Pp. 289-310 in Networks and Netwars: The Future of Terror, Crime, and Militancy, edited by John Arquilla and David Ronfeldt. Santa Monica, Calif.: Rand.

Gerlach, Luther, and V. Hine. 1970. People, Power and Change. Indianapolis: BobbsMerrill.

Gould, Roger V. 1991. "Multiple Networks and Mobilization in the Paris Commune, 1871." American Sociological Review 56:716-29. 


\section{American Journal of Sociology}

Granovetter, Mark. 1973. "The Strength of Weak Ties.” American Journal of Sociology $78: 1360-80$

. 1983. "The Strength of Weak Ties: A Network Theory Revisited." Sociological Theory 1:201-33.

. 1985. "Economic Action and Social Structure: The Problem of Embeddedness." American Journal of Sociology 91:481-510.

Gulati, Ranjay, and Maxim Sytch. 2007. "Dependence Asymmetry and Joint Dependence in Interorganizational Relationships.” Administrative Science Quarterly 52:32-69.

Hagopian, Frances. 2000. "Political Development, Revisited." Comparative Political Studies 33:880-911.

Hedström, Peter. 2005. Dissecting the Social: On the Principles of Analytical Sociology. Cambridge: Cambridge University Press.

Heider, Fritz. 1958. The Psychology of Interpersonal Relations. New York: Wiley.

Hunter, Floyd. 1953. Community Power Structure. Chapel Hill: University of North Carolina Press.

Ingram, Paul, and Peter Roberts. 2000. "Friendships among Competitors in the Sydney Hotel Industry." American Journal of Sociology 106:387-423.

Jones, Andrew W., Richard N. Hutchinson, Nella Van Dyke, Leslie Gates, and Michele Companion. 2001. "Coalition Form and Mobilization Effectiveness in Local Social Movements." Sociological Spectrum 21:207-31.

Kenis, Patrick, and David Knoke. 2002. "How Organizational Field Networks Shape Interorganizational Tie-Formation Rates." Academy of Management Review 27: 275-93.

Kenis, Patrick, and Volker Schneider. 1991. "Policy Networks and Policy Analysis: Scrutinizing a New Analytical Toolbox.” Pp. 25-62 in Policy Networks: Empirical Evidence and Theoretical Considerations, edited by Bernd Marin and Renate Mayntz. Boulder, Colo.: Westview.

Knight, Barry, and Peter Stokes. 1996. The Deficit in Civil Society in the United Kingdom. Working Paper 1. Foundation for Civil Society, Birmingham.

Knoke, David 1990. Organizing for Collective Action. New York: Aldine de Gruyter.

2. 2001. Changing Organizations: Business Networks in the New Political Economy. Boulder, Colo.: Westview.

Knoke, David, and David L. Rogers. 1979. "A Blockmodel Analysis of Interorganizational Networks." Sociology and Social Research 64:28-52.

Kogut, Bruce, and Gordon Walker. 2001. "The Small World of Germany and the Durability of National Networks." American Sociological Review 66:317-35.

Kornhauser, William. 1959. The Politics of Mass Society. Glencoe, Ill.: Free Press.

Krackhardt, David. 1992. "The Strength of Strong Ties: The Importance of Philos in Organizations." Pp. 216-39 in Networks and Organizations, edited by Nitin Nohria and Robert Eccles. Boston: Harvard Business School Press.

. 1994. "Graph Theoretical Dimensions of Informal Organizations." Pp. 89-111 in Computational Organization Theory, edited by Kathleen M. Carley and Michael J. Prietula. Hillsdale, N.J.: Lawrence Erlbaum.

Kriesi, Hanspeter. 2004. "Political Context and Opportunity." Pp. 67-90 in The Blackwell Companion to Social Movements, edited by Davis A. Snow, Sarah H. Soule, and Hanspeter Kriesi. Oxford: Blackwell.

Laumann, Edward O., John Galaskiewicz, and Peter Marsden. 1978. "Community Structure as Interorganizational Linkages." Annual Review of Sociology 4:455-84.

Laumann, Edward O., and David Knoke. 1987. The Organizational State: Social Choice in National Policy Domains. Madison: University of Wisconsin Press.

Laumann, Edward O., and Franz Pappi. 1973. "New Directions in the Study of Community Elites." American Sociological Review 38:212-30. 


\section{Civic Networks}

1976. Networks of Collective Action: A Perspective on Community Influence Systems. New York: Academic Press.

Lazega, Emmanuel, and Philippa Pattison. 2001. "Social Capital as Social Mechanisms and Collective Assets." Pp. 185-208 in Social Capital, edited by Nan Lin, Karen Cook, and Ronald Burt. New Brunswick, N.J.: Transaction.

Lémieux, Vincent. 1998. Les coalitions: Liens, transactions e contról. Paris: Presses Universitaires de France.

Lichterman, Paul. 1995. The Search for Political Community: American Activists Reinventing Commitment. Cambridge: Cambridge University Press.

Lincoln, James R., Michael L. Gerlach, and Christina L. Ahmadjian. 1996. "Keiretsu Networks and Corporate Performance in Japan." American Sociological Review 61: $67-88$.

Linz, Juan J. 1967. "Cleavages and Consensus in West German Politics: The Early Fifties." Pp. 283-321 in Party Systems and Voter Alignments, edited by Seymour M. Lipset and Stein Rokkan. New York: Free Press.

Locke, Richard M. 1995. Remaking the Italian Economy. Ithaca, N.Y.: Cornell University Press.

Lowe, Philip D., and Jane M. Goyder. 1983. Environmental Groups in Politics. London: Allen and Unwin.

Lowndes, Vivien, Lawrence Pratchett, and Gerry Stoker. 2001. "Trends in Public Participation, Part II: Citizens' Perspectives.” Public Administration 79:445-56.

Marsden, Peter. 1990. "Network Data and Measurement." Annual Review of Sociology 16:435-63.

McAdam, Doug, Sidney Tarrow, and Charles Tilly. 2001. Dynamics of Contention. New York: Cambridge University Press.

McCammon, Holly, and Karen Campbell. 2002. "Allies on the Road to Victory: Coalition Formation between the Suffragists and the Women's Christian Temperance Union." Mobilization 7:231-51.

Medearis, John. 2005. "Social Movements and Deliberative Democratic Theory." British Journal of Political Science 35:53-75.

Melucci, Alberto. 1996. Challenging Codes. Cambridge: Cambridge University Press.

Minkoff, Debra. 1997. "Producing Social Capital: National Social Movements and Civil Society." American Behavioral Scientist 40:606-19.

Mizruchi, Mark S. 1996. "What Do Interlocks Do? An Analysis, Critique, and Assessment of Research on Interlocking Directorates." Annual Review of Sociology 22:271-98.

Newman, Mark E., and Michelle Girvan. 2004. "Finding and Evaluating Community Structure in Networks." Physical Review E 69:026113.

Osa, Maryjane. 2003. "Networks in Opposition: Linking Organizations through Activists in the Polish People's Republic." Pp. 77-104 in Social Movements and Networks, edited by Mario Diani and Doug McAdam. Oxford: Oxford University Press.

Padgett, John F., and Christopher K. Ansell. 1993. "Robust Action and the Rise of the Medici, 1400-1434.” American Journal of Sociology 98:1259-1319.

Paxton, Pamela 1999. "Is Social Capital Declining in the United States? A Multiple Indicator Assessment." American Journal of Sociology 105:88-127.

Polsby, Nelson W. 1960. "How to Study Community Power: The Pluralist Alternative." Journal of Politics 22:474-84.

Powell, Walter W. 1990. "Neither Market Nor Hierarchy: Network Forms of Organizations." Research in Organizational Behavior 12:295-366.

Powell, Walter W., and Elisabeth Clemens. 1998. Private Action and the Public Good. New Haven, Conn.: Yale University Press.

Powell, Walter W., Douglas R. White, Kenneth W. Koput, and Jason Owen-Smith. 


\section{American Journal of Sociology}

2005. "Network Dynamics and Field Evolution: The Growth of Interganizational Collaboration in the Life Sciences." American Journal of Sociology 110:1132-1205.

Purdue, Derrick, Jörg Dürrschmidt, Peter Jowers, and Richard O'Doherty. 1997. "DIY Culture and Extended Milieux: LETS, Veggie Boxes and Festivals." Sociological Review 45:645-67.

Putnam, Robert D. 2000. Bowling Alone. New York: Simon \& Schuster.

Robins, Garry, Philippa Pattison, and Jodie Woolcock. 2005. "Small and Other Worlds: Global Network Structures from Local Processes.” American Journal of Sociology 110:894-936.

Rochon, Thomas R., and David S. Meyer, eds. 1997. Coalitions and Political Movements: The Lessons of the Nuclear Freeze. Boulder, Colo.: Lynne Rienner.

Rosenthal, Naomi, Meryl Fingrutd, Michele Ethier, Roberta Karant, and David McDonald. 1985. "Social Movements and Network Analysis: A Case Study of Nineteenth-century Women's Reform in New York State." American Journal of Sociology 90:1022-54.

Rucht, Dieter. 1989. "Environmental Movement Organizations in West Germany and France." Pp. 61-94 in Organizing for Change, edited by Bert Klandermans. Greenwich, Conn.: JAI Press.

Salancik, Gerald R. 1995. "WANTED: A Good Network Theory of Organization." Administrative Science Quarterly 40:345-49.

Sampson, Robert J., Doug McAdam, Heather MacIndoe, and Simón Weffer-Elizondo. 2005. "Civil Society Reconsidered: The Durable Nature and Community Structure of Collective Civic Action." American Journal of Sociology 111:673-714.

Sawer, Majer, and Abigail Groves. 1994. “'The Women's Lobby': Networks, Coalition Building and the Women of Middle Australia." Australian Journal of Political Science 29:435-59.

Skocpol, Theda. 2003. Diminishing Democracy: From Membership to Management in American Civic Life. Norman: University of Oklahoma Press.

Staggenborg, Susan. 1986. "Coalition Work in the Pro-choice Movement: Organizational and Environmental Opportunities and Constraints." Social Problems 33:623-41.

Taylor, Marylin. 2003. Public Policy in the Community. Basingstoke: Palgrave Macmillan.

Taylor, Verta, and Nancy Whittier. 1992. "“Collective Identity in Social Movement Communities: Lesbian Feminist Mobilization.” Pp. 104-32 in Frontiers in Social Movement Theory, edited by Aldon D. Morris and Carol McClurg Mueller. New Haven, Conn.: Yale University Press.

Walker, Gordon, Bruce Kogut, and Weijian Shan. 1997. "Social Capital, Structural Holes and the Formation of an Industry Network." Organization Science 8:109-25.

Warren, Mark E. 2001. Democracy and Association. Princeton, N.J.: Princeton University Press.

Watts, Duncan J. 1999. Small Worlds: The Dynamics of Networks between Order and Randomness. Princeton, N.J.: Princeton University Press.

Wuthnow, Robert 1998. Loose Connections: Joining Together in America's Fragmented Communities. Cambridge, Mass.: Harvard University Press.

Zald, Mayer N., and John D. McCarthy. 1987. Social Movements in an Organizational Society. New Brunswick, N.J.: Transaction. 